NBER WORKING PAPER SERIES

\title{
MAXIMIZING PREDICTABILITY IN THE STOCK AND BOND MARKETS
}

Andrew W. Lo

A. Craig MacKinlay

Working Paper No. 5027

\author{
NATIONAL BUREAU OF ECONOMIC RESEARCH \\ 1050 Massachusetts Avenue \\ Cambridge, MA 02138 \\ February 1995
}

We thank Andrea Beltratti, Hank Bessembinder, Kent Daniel, John Heaton, Bruce Lehmann, Krishna Ramaswamy, Guofu Zhou, and seminar participants at the Second International Conference of the IMI Group's Center for Research in Finance, the MIT IFSRC Symposium on the Statistical Properties of Stock Prices, the Society of Quantitative Analysts, the University of British Columbia, the University of Colorado, and the Western Finance Association for many helpful comments and suggestions. A portion of this research was completed during the first author's tenure as an Alfred P. Sloan Research Fellow and the second author's tenure as a Batterymarch Fellow. Research support from the Geewax-Terker Investments Research Fund (MacKinlay), the MIT Laboratory for Financial Engineering (Lo), and the National Science Foundation (Grant No. SES-8821583) is gratefully acknowledged. This paper is part of NBER's research program in Asset Pricing. Any opinions expressed are those of the authors and not those of the National Bureau of Economic Research.

(C) 1995 by Andrew W. Lo and A. Craig MacKinlay. All rights reserved. Short sections of text, not to exceed two paragraphs, may be quoted without explicit permission provided that full credit, including () notice, is given to the source. 


\title{
MAXIMIZING PREDICTABILITY IN THE STOCK AND BOND MARKETS
}

\begin{abstract}
We construct portfolios of stocks and of bonds that are maximally predictable with respect to a set of ex ante observable economic variables, and show that these levels of predictability are statistically significant, even after controlling for data-snooping biases. We disaggregate the sources for predictability by using several asset groups, including industry-sorted portfolios, and find that the sources of maximal predictability shift considerably across asset classes and sectors as the return-horizon changes. Using three out-of-sample measures of predictability, we show that the predictability of the maximally predictable portfolio is genuine and economically significant.
\end{abstract}

Andrew W. Lo

Sloan School of Management M.I.T.

Cambridge, MA 02139

and NBER

\author{
A. Craig MacKinlay \\ Department of Finance \\ The Wharton School \\ University of Pennsylvania \\ Philadelphia, PA 19104-6367 \\ and NBER
}




\section{Introduction}

The search for predictability in asset returns has occupied the attention of investors and academics since the advent of organized financial markets. While investors have an obvious financial interest in predictability, its economic importance can be traced to at least three distinct sources: implications for how aggregate fluctuations in the economy are transmitted to and from financial markets, implications for optimal consumption and investment policies, and implications for market efficiency. For example, several recent papers claim that the apparent predictability in long-horizon stock return indexes is due to business cycle movements and changes in aggregate risk premia. ${ }^{1}$ Others claim that such predictability is symptomatic of inefficient markets, markets populated with overreacting and irrational investors. ${ }^{2}$ And following both explanations is a growing number of proponents of market-timing or "tactical asset allocation", in which predictability is exploited, ostensibly to improve investors' risk-return trade-offs. ${ }^{3}$ Indeed, Roll (1988) has suggested that "The maturity of a science is often gauged by its success in predicting important phenomena".

For these reasons, many economists have undertaken the search for predictability in earnest and with great vigor. Indeed, the very attempt to improve the "fit" of theories to observations-Leamer's (1978) so-called "specification searches"-can be viewed as a search for predictability. But as important as it is, predictability is rarely maximized systematically in empirical investigations, even though it may dictate the course of the investigation at many critical junctures and, as a consequence, is maximized implicitly over time and over sequences of investigations.

In this paper, we maximize the predictability in asset returns explicitly by constructing portfolios of assets that are the most predictable, in a sense to be made precise below. Such explicit maximization can add several new insights to findings based on less formal methods. Perhaps the most obvious is that it yields an upper bound to what even the

\footnotetext{
${ }^{1}$ See Fama and French (1990) and Ferson and Harvey (1991b) for example.

${ }^{2}$ For example, see Chopra, Lakonishok, and Ritter (1992), DeBondt and Thaler (1985), and Lehmann (1990).

${ }^{3} \mathrm{~A}$ few of the most recent examples include Clarke et al. (1989), Droms (1989), Hardy (1990), Kester (1990), Lee and Rahman (1990, 1991), Shilling (1992), Sy (1990), Vandell and Stevens (1989), Wagner et al. (1992), and Weigel (1991). However, see Samuelson $(1989,1990)$ for a caution against such strategies.
} 
most industrious investigator will achieve in his search for predictability among portfolios. ${ }^{4}$ As such, it provides an informal yardstick against which other findings may be measured. For example, approximately 10 percent of the variation in the CRSP equal-weighted weekly return index from 1962 to 1992 can be explained by the previous week's returns--is this large or small? The answer will depend on whether the maximum predictability for weekly portfolio returns is 15 percent or 75 percent.

More importantly, the maximization of predictability can direct us towards more disaggregated sources of persistence and time-variation in asset returns, in the form of portfolio weights of the most predictable portfolio, and sensitivities of those weights to specific predictors, e.g., industrial production, dividend yield, etc. A primitive example of this kind of disaggregation is the lead/lag relation among size-sorted portfolios uncovered by Lo and MacKinlay (1990a), in which the predictability of weekly stock index returns is traced to the tendency for the returns of larger capitalization stocks to lead those of smaller stocks. The more general framework we shall introduce below includes lead/lag effects as a special case, but captures predictability explicitly as a function of time-varying economic risk premia rather than as a function of past returns only. In fact, the evidence for time-varying expected returns in the stock and bond markets in the form of ex ante economic variables that can forecast asset returns is now substantial. ${ }^{5}$ Our results add to those of the existing literature in three ways: (1) we estimate the "maximally predictable portfolio" or MPP, given a specific model of time-varying risk premia; (2) we compute the sensitivities of this MPP with respect to ex ante economic variables; and (3) we trace the sources of predictability, via the portfolio weights of the MPP, to specific industry sectors, market capitalization classes, and stock/bond/utilities classes, over various holding periods.

Of course, both implicit and explicit maximization of predictability are forms of "datasnooping" and may bias classical statistical inferences. But the biases from an explicit

\footnotetext{
${ }^{4}$ As will become apparent below, we maximize predictability across portfolios, holding fixed the set of regressors used to forecast asset returns. In a related paper, Foster and Smith (1994) maximize predictability across subsets of regressors, holding fixed the asset return to be predicted. Therefore, our upper bound obtains over a fixed set of regressors, while Foster and Smith's obtains over a fixed set of assets.

${ }^{5}$ See, for example, Chen (1991), Chen, Roll and Ross (1986), Engle, Lilien, and Robbins (1987), Fama and French (1990), Ferson (1989, 1990), Ferson and Harvey (1991), Ferson, Kandel, and Stambaugh (1987), Gibbons and Ferson (1985), Jegadeesh (1990), Keim and Stambaugh (1986), and Lo and MacKinlay (1988).
} 
maximization are far easier to quantify and correct for-which we do below-than those from a series of informal and haphazard searches. ${ }^{6}$ Moreover, we develop a procedure for maximizing predictability that does not impart any obvious data-snooping biases (although subtle biases may always arise), using an out-of-sample rolling estimation approach similar to that of Fama and MacBeth (1973). We use a subsample to estimate the optimal portfolio weights, form these portfolios with the returns from an adjacent subsample, and obtain estimates of predictability by rolling through the data.

When applied to monthly stock returns from 1947 to 1993 , we find that predictability can be increased considerably both by portfolio selection and by horizon selection. For example, if we consider as our universe of assets the 11 portfolios formed by industry or sector classification according to SIC codes, for an annual return-horizon the maximally predictable portfolio has an $R^{2}$ of 53 percent, whereas the largest $R^{2}$ of the 11 regressions of individual sector assets on the same predictors is 40 percent.

Moreover, the weights of the maximally predictable portfolio change dramatically with the horizon, pointing to differences across market capitalization and sectors for forecasting purposes. For example, using the 11 sector assets as our universe and a monthly returnhorizon, the maximally predictable portfolio has a substantial long position in the nondurables sector (with a portfolio weight of 215 percent), and a substantial short position in the durables sector (with a portfolio weight of -138 percent). However, at a semi-annual return-horizon, the maximally predictable portfolio is long in basic industries (108 percent), and short in construction (-90 percent). Although the portfolio weights are much less volatile for the shortsales-constrained cases, they still vary considerably with the return horizon. Such findings suggest distinct forecasting horizons for the various sector assets, and may signal important differences in how such groups of securities respond to economic events.

In Section 2, we motivate our interest in the MPP by showing that the typical twostep approach of searching for predictability-fitting a contemporaneous linear multi-factor model, and then predicting the factors - may significantly understate the true magnitude of

\footnotetext{
${ }^{6}$ For the biases of and possible corrections to such informal specification searches see Foster and Smith (1994), Iyengar and Greenhouse (1988), Leamer (1978), Lo and MacKinlay (1990b), and Ross (1987).
} 
predictability in asset returns and overstate the number of factors required to capture the predictability. In contrast, the MPP provides a more accurate assessment of the predictable variation. The MPP is developed more formally in Section 3 and an illustrative example of its economic relevance is provided. In Section 4, we apply these results to monthly stock and bond data from 1947 to 1993, and estimate the maximally predictable portfolio for three distinct asset groups: a five-asset group of stocks, bonds, and utilities; an eleven-asset group of sector portfolios; and a ten-asset group of size-sorted portfolios. To correct for the obvious biases imparted by maximizing predictability, we report Monte Carlo results for the statistical inference of the maximal $R^{2}$ s reported in Section 5. To gauge the economic significance of the maximally predictability portfolio, in Section 6 we present three outof-sample measures of the portfolio's predictability, measures that are not subject to the most obvious kinds of data-snooping biases associated with maximizing predictability. We conclude in Section 7.

\section{Motivation.}

An increasingly popular approach to investigating predictability in asset returns is to follow a two-step procedure: (1) construct a linear factor model of returns based on cross-sectional explanatory power, e.g., factor analysis, principal components decomposition, etc.; and (2) analyze the predictability of these factors. Such an approach is motivated by the substantial and still-growing literature on linear pricing models such as the CAPM, the APT, and its many variants in which expected returns are linearly related to contemporaneous "systematic" risk factors. Because time-variation in expected returns can be a source of return predictability, several recent studies have followed this two-step procedure, e.g., Chen (1991), Ferson and Harvey (1991a, 1991b, 1993), and Ferson and Korajcyzk (1993).

While the two-step approach can shed considerable light on the nature of asset return predictability-especially when the risk factors are known-it may not be as informative when the factors are unknown. For example, it is possible that the set of factors which best explain the cross-sectional variation in expected returns are relatively unpredictable, whereas other factors that can be used to predict expected returns are not nearly as useful 
contemporaneously in capturing the cross-sectional variation of expected returns. Therefore, focusing on the predictability of factors which are important contemporaneously may yield a very misleading picture of the true nature of predictability in asset returns.

To formalize this intuition, consider a simple example consisting of two assets, $\mathrm{A}$ and $\mathrm{B}$, which satisfy a linear two-factor model. In particular, let $R_{t}$ denote the $(2 \times 1)$-vector of de-meaned asset returns $\left[\begin{array}{ll}R_{a t} & R_{b t}\end{array}\right]^{\prime}$ and suppose that:

$$
R_{t}=\delta_{1} F_{1 t}+\delta_{2} F_{2 t}+\epsilon_{t}
$$

where $\delta_{1} \equiv\left[\begin{array}{ll}\delta_{a 1} & \delta_{b 1}\end{array}\right]^{\prime}, \delta_{2} \equiv\left[\begin{array}{ll}\delta_{a 2} & \delta_{b 2}\end{array}\right]^{\prime}, \epsilon_{t} \equiv\left[\begin{array}{ll}\epsilon_{a t} & \epsilon_{b t}\end{array}\right]^{\prime}$ is vector white noise with covariance matrix $\sigma_{\epsilon}^{2} \mathrm{I}$, and $F_{1 t}$ and $F_{2 t}$ are the two factors that drive the expected returns of $\mathrm{A}$ and $\mathrm{B}$. Without loss of generality, we assume that the two factors are mutually uncorrelated at all leads and lags, and have zero mean and unit variance, hence:

$$
\begin{gathered}
\mathrm{E}\left[F_{1 t}\right]=\mathrm{E}\left[F_{2 t}\right]=0, \quad \operatorname{Var}\left[F_{1 t}\right]=\operatorname{Var}\left[F_{2 t}\right]=1, \\
\operatorname{Cov}\left[F_{1 s}, F_{2 t}\right]=0 \quad \forall s, t .
\end{gathered}
$$

Now suppose that $F_{1 t}$ is unpredictable through time, while $F_{2 t}$ is predictable. In particular, suppose that $F_{1 t}$ is a white noise process, and that $F_{2 t}$ is an $\mathrm{AR}(1)$ :

$$
F_{1 t} \sim \text { White Noise } \quad, \quad F_{2 t}=\beta F_{2 t-1}+\eta_{t},|\beta| \in[0,1)
$$

where $\left\{\eta_{t}\right\}$ is a white noise process with variance $1-\beta^{2}$ and independent of $\left\{\epsilon_{t}\right\}$. Under these assumptions, expected returns are "explained" by two contemporaneous factors, of which one is white noise and the other is predictable. For later reference, we observe that under this linear two-factor model the contemporaneous covariance matrix and the first-order autocovariance matrix of $R_{t}$ are given by:

$$
\Gamma_{0}=\operatorname{Var}\left[R_{t}\right]=\delta_{1} \delta_{1}{ }^{\prime}+\delta_{2} \delta_{2}{ }^{\prime}+\sigma_{\epsilon}^{2} \mathrm{I}
$$




$$
\Gamma_{1}=\operatorname{Cov}\left[R_{t}, R_{t-1}\right]=\delta_{2} \delta_{2}^{\prime} \beta .
$$

For the remainder of this section, we shall assume that while (1) is the true data-generating process, it is unknown to investors.

When the true factors $F_{1 t}$ and $F_{2 t}$ are unobserved, the most common approach to estimating (1) is to perform some kind of factor analysis or principal components decomposition [see, for example, Brown and Weinstein (1983), Chamberlain (1983), Chamberlain and Rothschild (1983), Connor and Korajczyk (1986, 1988), Lehmann and Modest (1985), Roll and Ross (1980)]. For this reason, a natural focus for the sources of predictability are the extracted factors or principal components. In our simple two-asset example, the first principal component is a portfolio $\omega_{\mathrm{PC}_{1}}$ which corresponds to the normalized eigenvector of the largest eigenvalue of the contemporaneous covariance matrix $\Gamma_{0}$. This yields the portfolio return:

$$
R_{\mathrm{PC} 1, t} \equiv \omega_{\mathrm{PC1}}^{\prime} R_{t}
$$

which may be interpreted as the linear combination of the two assets which "explains" as much of the cross-sectional variation in returns as possible. In this sense, $R_{\mathrm{PC} 1, t}$ may be viewed as the [cross-sectionally] "most important" factor. Therefore, this is a natural focus for the sources of predictability in expected returns.

How predictable is this most important factor? One measure is the theoretical or population $R^{2}$ of a regression of $R_{\mathrm{PC} 1, t}$ on the lagged factors $F_{1 t-1}$ and $F_{2 t-1}$. This is given by:

$$
R^{2}\left[R_{\mathrm{PC} 1, t}\right]=\frac{\left(\omega_{\mathrm{PC} 1}^{\prime} \delta_{2} \beta\right)^{2}}{\omega_{\mathrm{PC} 1}^{\prime} \Gamma_{0} \omega_{\mathrm{PC} 1}} .
$$

Observe that only the factor loading $\delta_{2}$ of factor 2 appears in the numerator of (8). Since factor 1 is white noise, it contributes nothing to the predictability of $R_{\mathrm{PC} 1, t}$, hence $\delta_{1}$ plays no role in determining the $R^{2}$. However, $\delta_{1}$ does appear implicitly in the denominator of (8) since it affects the variance of $R_{\mathrm{PC} 1, t}$ [see (5)]. Therefore, it is easy to see how an important cross-sectional factor may not have much predictability. By increasing the factor loading $\delta_{1}$, 
the first factor becomes increasingly more important in the cross-section, but holding other parameters constant, this will decrease the predictability of $R_{\mathrm{PC} 1, t}$.

A second measure of predictability is the squared first-order autocorrelation coefficient of $R_{\mathrm{PC} 1, t}$, which corresponds to the $R^{2}$ of the regression of $R_{\mathrm{PC}_{1, t}}$ on $R_{\mathrm{PC} 1, t-1}$. This is given by the expression:

$$
\rho_{1}^{2}\left[R_{\mathrm{PC} 1, t}\right]=\frac{\left[\left(\omega_{\mathrm{PC} 1}^{\prime} \delta_{2}\right)^{2} \beta\right]^{2}}{\left(\omega_{\mathrm{PC} 1}^{\prime} \Gamma_{0} \omega_{\mathrm{PC} 1}\right)^{2}}
$$

For similar reasons, it is apparent from (9) that an important cross-sectional factor need not reflect much predictability.

For concreteness, consider the following numerical example:

$$
\begin{gathered}
R_{t}=\left(\begin{array}{l}
10.0 \\
15.0
\end{array}\right) F_{1 t}+\left(\begin{array}{l}
0.5 \\
1.0
\end{array}\right) F_{2 t}+\epsilon_{t} \\
\mathrm{E}\left[\epsilon_{t} \epsilon_{t}^{\prime}\right]=\sigma_{\epsilon}^{2} I, \quad \sigma_{\epsilon}^{2}=16, \beta=0.90 .
\end{gathered}
$$

Under these parameter values, the first principal component portfolio $R_{\mathrm{PC}_{1, t}}$ accounts for 95.5 percent of the cross-sectional variation in returns, i.e., when the eigenvalues of $\Gamma_{0}$ are normalized to sum to one, the largest eigenvalue is 0.955 . However, the predictability of $R_{\mathrm{PC} 1, t}$ as measured by $R^{2}\left[R_{\mathrm{PC} 1, t}\right]$ in (8) is a trivial 0.3 percent, and its squared own-autocorrelation is 0.0010 percent, despite the fact that factor 2 has an autocorrelation coefficient of 90 percent!

In Section 3, we shall propose an alternative to cross-sectional factors such as $R_{\mathrm{PC}_{1, t}}$ for measuring predictability: the maximally predictable portfolio or MPP. In contrast to $R_{\mathrm{PC}_{1, \mathrm{t}}}$ which is constructed by maximizing variance, the MPP is constructed by maximizing predictability or $R^{2}$. For this reason, it provides a more direct measure of the magnitude and sources of predictability in asset returns data. Although we shall develop the MPP more formally in the next section, it is instructive to anticipate those results by comparing the predictability of the MPP to that of $R_{\mathrm{PC}_{1,}}$ in this two-asset example.

According to Proposition 1 of Section 3 below, the MPP $\omega_{\text {MPP }}$ is defined to be the normalized eigenvector corresponding to the largest eigenvalue of the matrix $V^{-1} \tilde{\Gamma}_{0}$, where 
$\tilde{\Gamma}_{0}=\delta_{2} \delta_{2}{ }^{\prime} \rho^{2}$ is the variance-covariance matrix of the one-step-ahead forecast of $R_{t}$ using $F_{1 t-1}$ and $F_{2 t-1}$ [see Section 3 for further details and discussion]. Substituting $\omega_{\mathrm{MPP}}$ for $\omega_{\mathrm{PC} 1}$ in (7) and (8) then yields a comparable measure of predictability for the MPP: $R^{2}\left[R_{\mathrm{MPP}, t}\right]$.

By calibrating the parameter values of (1) to monthly data [measured in percentages], we may compare the predictability of the MPP to the PC1 portfolio directly. In particular, if we let:

$$
\begin{gathered}
R_{t}=\left(\begin{array}{l}
7.5 \\
3.5
\end{array}\right) F_{1 t}+\left(\begin{array}{l}
\delta_{a 2} \\
5.0
\end{array}\right) F_{2 t}+\epsilon_{t} \\
\mathrm{E}\left[\epsilon_{t} \epsilon_{t}^{\prime}\right]=\sigma_{\epsilon}^{2} I, \quad \sigma_{\epsilon}^{2}=16, \beta=0.90
\end{gathered}
$$

and let $\delta_{a 2}$ vary, we can see how well the two portfolios $\omega_{\mathrm{PC} 1}$ and $\omega_{\mathrm{MPP}}$ reflect the predictability inherent in the two assets.

Table 1 reports the $R^{2}$ measures for both portfolios under two different values for $\delta_{a 2}$. In the first panel, $\delta_{a 2}$ is set to 0.50 , in which case the stocks $\mathrm{A}$ and $\mathrm{B}$ have $R^{2}$ 's of 0.3 percent and 38.0 percent, respectively, and monthly standard deviations of 8.5 percent and 7.3 percent, respectively. In this case, observe that the $\mathrm{PC} 1$ portfolio has an $R^{2}$ of only 9.6 percent and a squared own-autocorrelation $\rho^{2}(1)$ of only 1.1 percent, and this despite the fact that the squared own-autocorrelation of stock B is 17.9 percent. In contrast, the MPP has an $R^{2}$ of 45.0 percent and a squared own-autocorrelation of 24.9 percent.

As $\delta_{a 2}$ is increased to 7.5 , factor 2 becomes more important in determining the expected return of stock $\mathrm{A}$, and its the monthly variance also increases to 11.3 percent. In this case, the $\mathrm{PC} 1$ portfolio more accurately reflects the predictability in $\mathrm{A}$ and $\mathrm{B}$, with an $R^{2}$ and squared own-autocorrelation of 39.7 percent and 19.5 percent, respectively. Nevertheless, the MPP exhibits slightly more predictability, with an $R^{2}$ and squared own-autocorrelation of 41.6 percent and 21.4 percent, respectively.

The empirical relevance of the difference in the $R^{2}$ of the PC1 portfolio and the MPP can also be considered. Using a sample of eleven sector portfolio returns and six predetermined factors we calculated the sample $R^{2}$. (See the empirical implementation section for details 
about these portfolios and factors.) Using monthly returns for the period 1947:1 to 1993:12, the sample $R^{2}$ of MPP is 12.0 percent, whereas the sample $R^{2}$ of $P C 1$ is only 7.2 percent. Similar results hold for semi-annual and annual returns. Using semi-annual returns the MPP $R^{2}$ is 31.5 percent and the $\mathrm{PC} 1 R^{2}$ is 15.4 percent and with annual returns the MPP $R^{2}$ is 52.5 percent and the $\mathrm{PC} 1 R^{2}$ is 35.5 percent. These results illustrate that empirically the differences in the level of predictability of the returns on these two portfolios can be substantial.

The simple numerical example presented illustrates the fact that while the $\mathrm{PC} 1$ portfolio may be interesting in studies of cross-section relations among asset returns, the MPP is more directly relevant when predictability is the object of interest. Further, the sample $R^{2}$ results suggest the difference can be important empirically. In the following sections, we shall define the MPP more precisely and examine its statistical and empirical properties at length.

\section{Maximizing Predictability.}

To define the predictability of a portfolio, we require some notation. Consider a collection of $n$ assets with returns $R_{t} \equiv\left[\begin{array}{llll}R_{1 t} & R_{2 t} & \cdots & R_{n t}\end{array}\right]^{\prime}$ and for convenience, assume the following throughout this section: ${ }^{7}$

(A) $R_{t}$ is a jointly stationary and ergodic stochastic process with finite expectation $\mathrm{E}\left[R_{t}\right]=$ $\mu \equiv\left[\begin{array}{llll}\mu_{1} & \mu_{2} & \cdots & \mu_{n}\end{array}\right]^{\prime}$ and finite autocovariance matrices $\mathrm{E}\left[\left(R_{t-k}-\mu\right)\left(R_{t}-\mu\right)^{\prime}\right]=\Gamma_{k}$ where with no loss of generality, we take $k \geq 0$ since $\Gamma_{k}=\Gamma_{-k}^{\prime}$.

For convenience, we shall refer to these $n$ assets as "primary" assets, assets to be used to construct the maximally predictable portfolio, but they can be portfolios too.

Denote by $Z_{t}$ an $n \times 1$ vector of de-meaned primary asset returns, i.e., $Z_{t} \equiv R_{t}-\mu$, and let $\tilde{Z}_{t}$ denote some forecast of $Z_{t}$ based on information available at time $t-1$, which

\footnotetext{
${ }^{7}$ Assumption (A) is made for notational simplicity, since stationarity allows us to eliminate time-indexes from population moments such as $\mu$ and $\Gamma_{k}$. However, there are several alternatives to stationarity and ergodicity that permit time-varying unconditional moments and still satisfy a law of large numbers and central limit theorem, which is essentially all we require for our purposes. The qualitative features of our results will not change under such alternatives, (e.g. weak dependence with moment conditions), but would merely require replacing expectations with corresponding probability limits of suitably defined time-averages. See, for example, Lo and MacKinlay (1990a) and White (1984).
} 
we denote by the information set $\Omega_{t-1}$. For simplicity, we assume that $\tilde{Z}_{t}$ is the conditional expectation of $Z_{t}$ with respect to $\Omega_{t-1}$, i.e.,

$$
\tilde{Z}_{t}=\mathrm{E}\left[Z_{t} \mid \Omega_{t-1}\right]
$$

which would be the optimal forecast under a quadratic loss function [although we are not assuming that such a loss function obtains]. We may then express $Z_{t}$ as:

$$
\begin{gathered}
Z_{t}=\mathrm{E}\left[Z_{t} \mid \Omega_{t-1}\right]+\epsilon_{t}=\tilde{Z}_{t}+\epsilon_{t} \\
\mathrm{E}\left[\epsilon_{t} \mid \Omega_{t-1}\right]=0 \quad, \quad \operatorname{Var}\left[\epsilon_{t} \mid \Omega_{t-1}\right]=\Sigma
\end{gathered}
$$

Included in the information set $\Omega_{t-1}$ are ex ante observable economic variables such as dividend yield, various interest rate spreads, earnings announcements, and other "leading" economic indicators. Therefore, with a suitably defined intercept term, (15)-(16) contains conditional versions of the CAPM [see Merton (1973), Constantinides (1980), and Bossaerts and Green (1989)], a dynamic multi-factor APT [Ohlson and Garman (1980) and Connor and Korajczyk (1989)], and virtually all other linear asset pricing models as special cases.

We shall also assume throughout that the $\epsilon_{t}$ s are conditionally homoskedastic and that the information structure $\left\{\Omega_{t}\right\}$ is well-behaved enough to ensure that $\tilde{Z}_{t}$ is also a stationary and ergodic stochastic process. Note that the conditional homoskedasticity of the $\epsilon_{t} s$ does not restrict the $Z_{t}$ s to be conditionally homoskedastic; conditional heteroskedasticity in $Z_{t}$ is captured explicitly by heteroskedasticity in $\tilde{Z}_{t}$. Moreover, it is a simple matter to build additional heteroskedasticity into $Z_{t}$ by allowing $\epsilon_{t}$ to exhibit conditional heteroskedasticity.

Although we have now given just enough structure to derive an explicit expression for the maximally predictable portfolio of the primary assets $Z_{t}$, it is worthwhile to consider some specific examples of the conditional expectation $\tilde{Z}_{t}$ since any empirical implementation will require placing further structure on it. For example, perhaps the simplest specification 
of $\tilde{Z}_{t}$ is a $p$-th order vector autoregression:

$$
Z_{t}=A_{1} \cdot Z_{t-1}+A_{2} \cdot Z_{t-2}+\cdots+A_{p} \cdot Z_{t-p}+\epsilon_{t}
$$

where the $A_{i}$ s are $(n \times n)$-matrices of coefficients. In this case, the forecast $\tilde{Z}_{t}$ is based only on lagged returns $Z_{t-k}, k=1, \ldots, p$, hence such a specification is most useful for examining simple departures from the pure random walk hypothesis.

More generally, suppose that the forecast $\tilde{Z}_{t}$ is a linear function of the $(k \times 1)$-vector of economic variables $X_{t-1}$ contained in $\Omega_{t-1}$, hence:

$$
Z_{t}=A \cdot X_{t-1}+\epsilon_{t}
$$

where $A$ is an $(n \times k)$-matrix of coefficients. The presence of just one lag of $X_{t}$ in (7) is for notational convenience only since higher order lags may readily be subsumed in $X_{t-1}$ by enlarging the dimension of the vector [note that $k$ may be larger than $n$ ].

Expression (18) may be viewed as a conditional version of a linear factor model since $Z_{t}$ is a linear function of economic variables observable at $t-1 .^{8}$ To underscore this factorpricing interpretation, we shall refer to the matrix $A$ of coefficients as the "factor loadings" and the predictors $X_{t-1}$ as "conditional factors". However, it should be emphasized that a "structural" factor-model for our return-generating process, one that links expected returns to contemporaneous risk premia (such as the security market line of the CAPM), is not required by our framework. But even if such a structural factor-model exists, the contemporaneous factors or risk premia are almost always written as linear functions of ex ante economic variables, especially when applying them to time series data. Therefore, the simple specification (18) is considerably more general than it may appear to be.

Returning to the general formulation (15), let $\gamma$ denote a particular linear combination of the primary assets in $Z_{t}$, and consider the predictability of this linear combination, as

\footnotetext{
${ }^{8}$ Examples of such a specification in the recent literature include Chen, Roll, and Ross (1986), Engle, Lilien, and Robbins (1987), Ferson (1989, 1990), Ferson and Harvey (1991b), and Harvey (1989).
} 
measured by the well-known coefficient of determination:

$$
R^{2}(\gamma) \equiv 1-\frac{\operatorname{Var}\left[\gamma^{\prime} \epsilon_{t}\right]}{\operatorname{Var}\left[\gamma^{\prime} Z_{t}\right]}=\frac{\operatorname{Var}\left[\gamma^{\prime} \tilde{Z}_{t}\right]}{\operatorname{Var}\left[\gamma^{\prime} Z_{t}\right]}=\frac{\gamma^{\prime} \tilde{\Gamma}_{0} \gamma}{\gamma^{\prime} \Gamma_{0} \gamma}
$$

where

$$
\begin{aligned}
& \tilde{\Gamma}_{\mathrm{o}} \equiv \operatorname{Var}\left[\tilde{Z}_{t}\right]=\mathrm{E}\left[\tilde{Z}_{t} \tilde{Z}_{t}^{\prime}\right] \\
& \Gamma_{\mathrm{o}} \equiv \operatorname{Var}\left[Z_{t}\right]=\mathrm{E}\left[Z_{t} Z_{t}^{\prime}\right]
\end{aligned}
$$

$R^{2}(\gamma)$ is simply the fraction of the variability in the portfolio return $\gamma^{\prime} Z_{t}$ explained by its conditional expectation, $\gamma^{\prime} \tilde{Z}_{t}$. Maximizing the predictability of a portfolio of $Z_{t}$ then amounts to maximizing $R^{2}(\gamma)$ subject to the constraint that $\gamma$ is a portfolio, i.e., $\gamma^{\prime} \iota=1$. But since $R^{2}(\gamma)=R^{2}(c \gamma)$ for any constant $c$, the constrained maximization is formally equivalent to maximizing $R^{2}$ over all $\gamma$, and then rescaling this globally optimal $\gamma$ so that its components sum to unity. Such a maximization is straightforward and yields an explicit expression for the maximum $R^{2}$ and its maximizer, given by Gantmacher (1959) and Box and Tiao (1977): ${ }^{9}$

Proposition 1 [Gantmacher (1959), Box and Tiao (1977)]: The maximum of $R^{2}(\gamma)$ with respect to $\gamma$ is given by the largest eigenvalue $\lambda^{*}$ of the matrix $\mathrm{B} \equiv \Gamma_{0}^{-1} \tilde{\Gamma}_{0}$, and is attained by the eigenvector $\gamma^{*}$ associated with the largest eigenvalue of B. Similarly, the minimum of $R^{2}(\gamma)$ with respect to $\gamma$ is given by the smallest eigenvalue $\lambda_{*}$ of $\mathrm{B}$ and is attained by the eigenvector $\gamma_{*}$ associated with the smallest eigenvalue of $\mathrm{B}$.

Proof: See the appendix.

This proposition states that the maximum $R^{2}$ attainable by any portfolio $\gamma$ is simply the largest eigenvalue $\lambda^{*}$ of the matrix $B$, and that the maximally predictable portfolio $\gamma^{*}$ is the corresponding eigenvector [properly normalized]. Note that by symmetry this proposition gives not only the maximal $R^{2}$ attainable, but also the minimal $R^{2}$ attainable, i.e., the portfolio that is closest to a random walk. For convenience, we shall refer to the maximally

\footnotetext{
${ }^{9}$ Two closely related techniques are the multivariate index model the reduced rank regression model; see Reinsel (1983) and Velu, Reinsel, and Wichern (1986).
} 
predictable portfolio $\gamma^{*}$ as simply the "MPP". To develop some intuition for the economic relevance of the MPP, we consider a specific example in the next section.

\subsection{Example: A One-Factor Model.}

Suppose we forecast excess returns $Z_{t}$ with only a single factor $X_{t-1}$, so that we hypothesize the relation:

$$
\begin{gathered}
Z_{t}=\beta \cdot X_{t-1}+\epsilon_{t} \\
\mathrm{E}\left[\epsilon_{t} \mid X_{t-1}\right]=0 \quad, \quad \operatorname{Var}\left[\epsilon_{t} \mid X_{t-1}\right]=\Sigma
\end{gathered}
$$

where $\beta$ is an $(n \times 1)$-vector of factor loadings, and $\Sigma$ is any positive definite covariance matrix (not necessarily diagonal). Such a relation might arise from the CAPM, in which case $X_{t-1}$ is the period $t-1$ forecast of the market risk premium at time $t$. In this simple case, the relevant matrices may be calculated in closed-form as:

$$
\begin{aligned}
& \tilde{\Gamma}_{0} \equiv \operatorname{Var}\left[\tilde{Z}_{t}\right]=\sigma_{x}^{2} \beta \beta^{\prime} \\
& \Gamma_{0} \equiv \operatorname{Var}\left[Z_{t}\right]=\sigma_{x}^{2} \beta \beta^{\prime}+\Sigma
\end{aligned}
$$

where $\sigma_{x}^{2} \equiv \operatorname{Var}\left[X_{t-1}\right]$. The MPP $\gamma^{*}$ and its $R^{2}$ are then given by:

$$
\begin{aligned}
\gamma^{*} & =\frac{1}{\iota^{\prime} \Sigma^{-1} \beta} \Sigma^{-1} \beta \\
\lambda^{*}=R^{2}\left(\gamma^{*}\right) & =\frac{\sigma_{x}^{2} \beta^{\prime} \Sigma^{-1} \beta}{1+\sigma_{x}^{2} \beta^{\prime} \Sigma^{-1} \beta} .
\end{aligned}
$$

To develop further intuition for (26) and (27), suppose that $\Sigma=\sigma_{\epsilon}^{2} I$, so that the MPP and its $R^{2}$ reduce to:

$$
\begin{aligned}
\gamma^{*} & =\frac{1}{\iota^{\prime} \beta} \beta \\
\lambda^{*}=R^{2}\left(\gamma^{*}\right) & =\frac{\beta^{\prime} \beta \sigma_{x}^{2} / \sigma_{\epsilon}^{2}}{1+\beta^{\prime} \beta \sigma_{x}^{2} / \sigma_{\epsilon}^{2}} .
\end{aligned}
$$


Not surprisingly, with cross-sectionally uncorrelated errors, the MPP has weights directly proportional to the assets' betas. The larger the beta, the more predictable that asset's future return will be ceteris paribus, hence the MPP should place more weight on that asset. As expected, $R^{2}\left(\gamma^{*}\right)$ is an increasing function of the "signal-to-noise" ratio $\sigma_{x}^{2} / \sigma_{\epsilon}$. But interestingly, the MPP weights $\gamma^{*}$ are not, and do not even depend on the $\sigma_{j}^{2}$ s. This, of course, is an artifact of our extreme assumption that the assets' variances are identical. If, for example, we assumed that $\Sigma$ were a diagonal matrix with elements $\sigma_{j}^{2}, j=1, \ldots, n$, then the portfolio weights $\gamma_{j}^{2}$ would be proportional to $\beta_{j} / \sigma_{j}^{2}$. The larger the $\beta_{j}$, the more weight asset $j$ will have in the MPP, and the larger the $\sigma_{j}^{2}$, the less weight it will have.

Since the level of predictability of $\gamma^{*}$ does depend on how important $X_{t-1}$ is in determining the variability of $Z_{t}$, in the case where $\Sigma=\sigma_{\varepsilon}^{2} I$ as the signal-to-noise ratio increases the $R^{2}$ of the MPP also increases, eventually approaching unity as $\sigma_{x}^{2} / \sigma_{\epsilon}^{2}$ increases without bound. Also, from (29) it is apparent that $R^{2}\left(\gamma^{*}\right)$ increases with the number of assets ceteris paribus, since $\beta^{\prime} \beta$ is simply the sum of squared betas. Of course, even in the most general case $R^{2}\left(\gamma^{*}\right)$ must be a non-decreasing function of the number of assets, since it is always possible to put zero weight on any newly introduced assets.

\section{An Empirical Implementation.}

To implement the results of Section 3, we must first develop a suitable forecasting model for the vector of excess returns $Z_{t}$. We consider three sets of primary assets $Z_{t}$ from 1947:1 to 1993:12: (1) a five-asset group, consisting of the S\&P 500, a small stock index, a government bond index, a corporate bond index, and a utilities index; (2) a ten-asset group consisting of deciles of size-sorted portfolios constructed from the CRSP monthly returns file; and (3) an eleven-asset group of sector-sorted portfolios, also constructed from CRSP. The eleven sector portfolios are defined according to SIC code classifications: (1) wholesale and retail trade;

(2) services; (3) non-durable goods; (4) construction; (5) capital goods; (6) durable goods; (7) finance, real estate, and insurance; (8) transportation; (9) basic industries; (10) utilities; and (11) coal and oil. Within each portfolio, the size-sorted portfolios and the sector-sorted portfolios are value-weighted. 
Despite the fact that monthly stock returns are available as early as $1926: 1$, we limit our attention to the post-war sample period because data for some of our conditional factors are only available as of 1947:1. However, a more compelling reason for using the shorter sample period is to minimize the impact of the Great Depression era on our inferences. It may be argued that the Great Depression should not be omitted from the sample because it is a bona fide structural phenomenon which should be allowed to influence parameter estimates accordingly. Viewed in this way, the Depression years are not outliers but valuable observations that may yield important information about the current structure of returns. But because the structure of the economy and, in particular, the organization of financial markets underwent such dramatic changes during this period, mainly in response to the stock market crash of October 1929 and the ensuing Great Depression, our inferences may be more germane to contemporary phenomena if we limit our estimation to the period after such changes were in place.

Of course, there are occasions when it is these very changes that we are interested in modeling, or when the presence of such changes is critical to the model at hand. But in such cases the structural shifts must generally be modeled explicitly, otherwise its effects are likely to be "averaged" out and confounded with other phenomena. ${ }^{10}$ Since these structural changes are not the focus of our current application, we confine our attention to post-war data only.

\subsection{The Conditional Factors.}

In developing forecasting models for the three groups of assets, we draw on the substantial literature documenting the time-variation in expected stock returns to select our conditional factors. From empirical studies by Breen, Glosten, and Jagannathan (1989), Chen (1991), Chen, Roll, and Ross (1986), Estrella and Hardouvelis (1991), Ferson (1990), Ferson and Harvey (1991b), Kale, Hakansson, and Platt (1991), Keim and Stambaugh (1986), Rozeff (1984), and many others, variables such as the growth in industrial production, dividend yield, and default and term spreads on fixed income instruments have been shown to have

\footnotetext{
${ }^{10}$ There are many examples of models that do capture structural shifts, such as Goldfeld and Quandt (1973), Hamilton (1989), and Sclove (1983).
} 
forecast power. Also, the asymmetric lead/lag relations among size-sorted portfolios that Lo and MacKinlay (1990a) document suggest that lagged returns may have forecast power. Therefore, we were led to construct the following variables:

DY $_{t}$ Dividend yield, defined as the aggregated dividends for the CRSP value-weighted index for the 12-month period ending at the end of month $t$ divided by the index value at the end of month $t$.

$\mathrm{DEF}_{t}$ The default spread, defined as the average weekly yield for low grade bonds in month $t$ minus the average weekly yield for long-term government bonds (maturity greater than 10 years) in month $t$. The low grade bonds are rated Baa.

$\mathrm{MAT}_{t}$ The maturity spread, defined as the average weekly yield on long-term government bonds in month $t$ minus the average weekly yield from the auctions of 3-month Treasury bills in month $t$.

$\mathrm{SPR}_{t}$ The S\&P500 Index return, defined as the monthly return on a value-weighted portfolio of 500 common stocks.

$\mathrm{IRT}_{t}$ The interest rate trend, defined as the monthly change of the average weekly yield on long-term government bonds.

Of course, there is a possible pre-test bias in our choosing these variables based on prior empirical studies. For example, Foster and Smith (1994) show that choosing $k$ out of $m$ regressors $(k<m)$ to maximize $R^{2}$ can yield seemingly significant $R^{2}$ s even when no relation exists between the dependent variable and the regressors. They show that such a specification search may explain the findings of Campbell (1987), Ferson and Harvey (1991a), and Keim and Stambaugh (1986). ${ }^{11}$

\footnotetext{
${ }^{11}$ However, using similar conditional factors, Bessembinder and Chan (1992) find similar levels of predictability for various commodity and currency futures which are nearly uncorrelated with equity returns. This is perhaps the most convincing empirical evidence to date for the genuine forecast power of dividend yields, short-term interest rate yields, and the default premium.
} 
Unfortunately, Foster and Smith's (1994) pre-test bias cannot easily be corrected in our application, for the simple reason that our selection procedure does not correspond precisely to choosing the "best" $k$ regressors out of $m$. There is no doubt that prior empirical findings have influenced our choice of conditional factors, but in much subtler ways than this. In particular, theoretical considerations have also played a part in our choice, both in which variables to include and which to exclude. For example, even though a January indicator variable has been shown to have some predictive power, we have not included it as a conditional factor because we have no strong theoretical motivation for such a variable.

Because a combination of empirical and theoretical considerations has influenced our choice of conditional factors, Foster and Smith's (1994) corrections are not directly applicable. Moreover, if we apply their corrections without actually searching for the best $k$ of $m$ regressors, we will almost surely never find predictability even if it exists, i.e., tests for predictability will have no power against economically plausible alternative hypotheses of predictable returns. Therefore, other than alerting readers to the possibility of pre-test biases in our selection of conditional factors, there is little else that we can do to "correct" for this ubiquitous problem.

\subsection{Time-Varying Betas.}

Perhaps the most common obstacle to reliable forecasting in financial markets is the timevariation of parameters of interest, such as covariances, cross-autocorrelations, and betas. ${ }^{12}$ For example, the asymmetric lead/lag effects among size-sorted portfolios that Lo and MacKinlay (1990a) document as a source of profitability for contrarian trading strategies varies considerably from one time period to the next.

To capture some of these instabilities, we propose the following simple time-varying beta model for the primary assets $Z_{t}$ :

$$
\begin{gathered}
Z_{t}=\alpha+\beta_{1} \cdot \mathrm{DY}_{t-1}+\beta_{2} \cdot \mathrm{DEF}_{t-1}+\beta_{3} \cdot \mathrm{MAT}_{t-1}+\beta_{4} \cdot \mathrm{IRT}_{t-1}+ \\
\beta_{5 t-1} \cdot \mathrm{SPR}_{t-1}+\epsilon_{t}
\end{gathered}
$$

\footnotetext{
${ }^{12}$ Several recent studies have documented the time-variation in asset pricing parameters, e.g., Ferson (1989), Ferson and Harvey (1991), Ferson, Kandel, and Stambaugh (1987), and Harvey (1989).
} 


$$
\beta_{5 t-1}=\delta_{0}+\delta_{1} \cdot \mathrm{DY} \mathrm{Y}_{t-1}
$$

The inclusion of $\mathrm{SPR}_{t-1}$, a portfolio dominated by large firms, allows us to capture the asymmetric lead/lag relation of Lo and MacKinlay (1990a), in which the returns of large firms can forecast those of small firms, but not vice-versa. Since we have expressed the coefficient $\beta_{5 t-1}$ of $\mathrm{SPR}_{t-1}$ as a deterministic linear function of the dividend yield $\mathrm{DY} t, \beta_{5 t-1}$ can vary through time and has the potential to capture instabilities in a systematic way. The fact that (31) is deterministic allows us to estimate (30) consistently by ordinary least squares regression, since by substitution we have:

$$
\begin{gathered}
Z_{t}=\alpha+\beta_{1} \cdot \mathrm{DY}_{t-1}+\beta_{2} \cdot \mathrm{DEF}_{t-1}+\beta_{3} \cdot \mathrm{MAT}_{t-1}+\beta_{4} \cdot \mathrm{IRT}_{t-1}+ \\
\left(\delta_{0}+\delta_{1} \cdot \mathrm{DY}_{t-1}\right) \cdot \mathrm{SPR}_{t-1}+\epsilon_{t} \\
=\alpha+\beta_{1} \cdot \mathrm{DY}_{t-1}+\beta_{2} \cdot \mathrm{DEF}_{t-1}+\beta_{3} \cdot \mathrm{MAT}_{t-1}+\beta_{4} \cdot \mathrm{IRT}_{t-1}+ \\
\delta_{0} \cdot \mathrm{SPR}_{t-1}+\delta_{1} \cdot \mathrm{DY}_{t-1} \cdot \mathrm{SPR}_{t-1}+\epsilon_{t} .
\end{gathered}
$$

Therefore, we need only add the interaction term $\mathrm{SPDY}_{t-1} \equiv \mathrm{DY}_{t-1} \cdot \mathrm{SPR}_{t-1}$ to our list of five regressors to estimate the time-varying parameter regression model $(30)-(31)$.

In principle, we can model all of the factor loadings as time-varying. However, the "curse of dimensionality" would arise, as well as the peril of overfitting the model. Moreover, the evidence in Ferson and Harvey (1991, Table 8) suggests that the predictability in monthly size and sector portfolios is primarily due to changing risk-premia, not changing betas. Therefore, our decision to leave $\beta_{1}$ through $\beta_{4}$ fixed through time is unlikely to be very restrictive.

\subsection{Estimating the Conditional Factor Model.}

Tables 2, 3, and 4 report ordinary least squares estimates of the conditional factor model (30)-(31) for the three groups of assets, respectively: the $5 \times 1$-vector of stocks, bonds, and utilities (SBU), the $10 \times 1$-vector of size deciles (SIZE), and the $11 \times 1$-vector of sector portfolios (SECTOR). Table $2 \mathrm{a}$ contains results for monthly SBU returns, Table $2 \mathrm{~b}$ contains semi-annual results, and Table $2 \mathrm{c}$ contains annual results, and similarly for Tables $3 \mathrm{a}-\mathrm{c}$ and $4 \mathrm{a}-\mathrm{c}$. We perform all multi-horizon return calculations with non-overlapping returns, since 
Monte Carlo and asymptotic calculations in Lo and MacKinlay (1989) and Richardson and Stock (1990) show that overlapping returns can bias inferences substantially.

The performance of the conditional factors in the regressions of Tables 2-4 are largely consistent with findings in the recent empirical literature. Among the equity assets, the dividend yield is positively related to future returns and generally significant at the 5 percent level. The default premium generally has little incremental explanatory power for future returns. Additional analysis indicates that its usual explanatory power is captured by the interest rate trend variable. The maturity premium has predictive power mostly for the utilities asset at longer horizons ( 6 and 12 months). In contrast, the S\&P 500 Index Return and the interest rate trend variables are strongest at the monthly horizon, the former affecting expected returns positively, and the latter negatively. For the bond assets, most of the forecastability is from the positive relation with the maturity spread.

From Tables $2-4$, it is also apparent that the market betas for monthly equity returns exhibit substantial time-variation, since the SPDY regressor is significant at the 5 percent level for the small stocks in Table $2 \mathrm{a}$, and for most of the assets in Tables $3 \mathrm{a}$ and $4 \mathrm{a}$. In these cases, the estimated coefficient of SPDY is consistently negative, indicating that the sensitivity of equity assets to the lagged aggregate market return declines as the dividend yield rises. Note that in each of these cases DY has additional explanatory power as a separate regressor, as its estimated coefficient is also significant at conventional levels.

As the return horizon increases, the market beta and the time-variation in market betas remains significant for the equity assets. For example, in Tables $2 b, 3 b$, and $4 b$, where semiannual asset returns are regressed on the conditional factors, the coefficients for SPR and SPDY are statistically significant in many of the regressions. Also, DY is still significant in the longer-horizon regressions, and in all cases the $R^{2}$ increases with the horizon. In particular, whereas the $R^{2}$ s for monthly asset returns reported in Tables 2a, 3a, and 4a range from 3 to 9 percent, the $R^{2}$ s for annual asset returns range from 16 to 44 percent in Tables 2c, 3c, and $4 \mathrm{c} .^{13}$

\footnotetext{
${ }^{13}$ Note that the longer-horizon returns are non-overlapping. In some unpublished Monte Carlo simulations, we have shown that overlapping returns can induce unusually high $R^{2}$ s even when the conditional factors are statistically independent of the long-horizon returns. See also Richardson and Stock (1990).
} 
Of course, like any other statistic, the $R^{2}$ is a point estimate subject to sampling variation. Since longer horizon returns yield fewer non-overlapping observations, we might expect the $R^{2}$ s from such regressions to exhibit larger fluctuations, with more extreme values than regressions for monthly data. We shall deal explicitly with the sampling theory of the $R^{2}$ in Section 5 .

\subsection{Maximizing Predictability.}

Given the estimated conditional factor models in Tables $2-4$, we can readily construct the (sample or estimated) MPPs according to Proposition 1. Given the estimate $\hat{\mathrm{B}} \equiv \hat{\Gamma}_{o}^{-1} \hat{\tilde{\Gamma}}_{o}$, the estimated MPP $\hat{\gamma}^{*}$ is simply the eigenvector corresponding to the largest eigenvalue of $\hat{B}$.

We will also have occasion to consider the constrained MPP $\gamma_{c}^{*}$, constrained to have nonnegative portfolio weights. It will become apparent below that an unconstrained maximization of predictability yields considerably more extreme and unstable portfolio weights than a constrained maximization. Moreover, for many investors, the constrained case may be of more practical relevance. Although we do not have a closed-form expression for $\gamma_{c}^{*}$, it is a simple matter to calculate it numerically. Again, given $\hat{\mathrm{B}}$, we may obtain $\hat{\gamma}_{c}^{*}$ in a similar manner.

In Table 5, we report the conditional factor model of the maximally predictable SBU portfolio, constrained and unconstrained, for monthly, semi-annual, and annual return horizons using the factors of Section 4.1. The patterns of the estimated coefficients are largely consistent with those of Tables 2a-c: the coefficient of the interaction variable SPDY is negative, though insignificant for monthly returns; the coefficient of dividend yield DY is positive and significant for all portfolios; and the maximal $R^{2}$ increases with the horizon.

As expected the maximal $R^{2} \mathrm{~s}$ are larger than the largest $R^{2} \mathrm{~s}$ of the individual portfolio regressions. For example, the monthly constrained maximal $R^{2}$ is 9 percent, and the S\&P 500 regression in Table $2 \mathrm{a}$ has a $R^{2} \mathrm{~s}$ of 7 percent. There is somewhat more improvement for longer return horizons. For example, at an annual horizon the unconstrained maximal $R^{2}$ is 50 percent, whereas the $R^{2}$ s for the annual returns of the five individual assets in Table 2c range from 34 to 43 percent.

Tables 6 and 7 exhibit similar findings for the SIZE and SECTOR assets. The $R^{2}$ s of 
monthly size portfolios range from 6 to 8 percent in Table 3a, whereas Table 6 reports the unconstrained maximal $R^{2}$ to be 12 , and the constrained to be 8 percent. But at an annual horizon, the $R^{2}$ s for individual size portfolios range from 23 to 44 percent, while the maximal constrained and unconstrained $R^{2}$ s from Table 6 are 45 and 61 percent respectively.

Tables 5-7 also show that the importance of the shortsales constraint for maximizing predictability depends critically on the particular set of assets over which predictability is being maximized. From Table 5, it is apparent that the shortsales constraint has little effect on the levels of the maximal $R^{2}$ for the five SBU assets. Such a constraint reduces the maximal $R^{2}$ by only 1 percentage point for semi-annual returns, and is not binding for annual returns. However, this is not the case for either the ten SIZE assets or the eleven SECTOR assets. Tables 6 and 7 show that when the shortsales constraint is imposed, maximal $R^{2} \mathrm{~s}$ drop dramatically, from 36 to 24 percent for semi-annual SIZE assets and from 32 to 25 percent for semi-annual SECTOR assets.

\subsection{The Maximally Predictable Portfolios.}

Whereas the coefficients of the regressions in Tables 5-7 measure the sensitivity of the MPP to various factors, it is the portfolio weights of the MPPs that tell us which assets are the most importance sources of predictability. Table 8 reports these portfolio weights for the three sets of assets, SBU, SIZE, and SECTOR.

Perhaps the most striking feature of Table 8 is how these portfolio weights change with the horizon. For example, the unconstrained maximally predictable SIZE portfolio has an extreme long position in decile 2 for monthly returns but an extreme short position for semiannual returns. The maximally predictable SECTOR and SBU portfolios exhibit similar patterns across horizons but the weights are much less extreme. These changing weights are consistent with a changing covariance structure among the assets over horizons; as the structure changes, so must the portfolio weights to maximize predictability.

When the shortsales constraint is imposed, the portfolio weights vary less extremely (by construction of course, since they are bounded between 0 and 1), but they still shift with the return horizon. For example, the constrained maximally predictable SBU portfolio is split between the S\&P500 and corporate bonds for monthly returns, but contains all assets for 
annual returns. More interestingly, the constrained maximally predictable SIZE portfolio is invested in decile 1 for monthly returns, but is concentrated in deciles 8,9 , and 10 for annual returns.

That the larger capitalization stocks should play so central a role in maximizing predictability among SIZE assets is quite unexpected, since it is the smaller stocks that are generally more highly autocorrelated. However, as the example in Section 3.2 illustrates, it is important to distinguish between the factors that predict returns and the assets that are most predictable. In the case of the SIZE assets, one explanation might be that over longer horizons, factors such as industrial production and dividend yield become more important for the larger companies as they track general business trends closer than smaller companies (see Tables $3 \mathrm{a}-3 \mathrm{~d}$ ).

Further insights concerning the sources of predictability are contained in the SECTOR portfolio weights. The constrained MPP for monthly SECTOR returns is invested in two assets: construction; and finance, real estate, and insurance. However, in the long-run, the composition of this portfolio changes dramatically, consisting mostly of two completely different assets: basic industries; and utilities. This indicates that the sources of timevariation in expected returns is highly dependent on the return horizon. The sectors that are important for maximizing predictability for monthly returns may be quite different from those that maximize predictability for returns over longer horizons.

\section{Statistical Inference for the Maximal $R^{2}$.}

Although the magnitudes of the sample $R^{2}$ s of Section 4 suggest the presence of genuine predictability in stock returns, we must still consider data-snooping biases imparted by our in-sample maximization procedure. It is a well-known fact that the maximum of a collection of identically distributed random variables does not have the same distribution as the individual maximands. However, it is not always an easy task to deduce the distribution of the maximum, especially when the individual variables are not statistically independent as in our current application. Moreover, maximizing the $R^{2}$ over a continuum of portfolio weights cannot be easily re-cast into the maximum of a discrete set of random variables. 
Therefore, much of our inferences must be guided by Monte Carlo simulation experiments in which the sampling distribution of $R^{2}$ and related statistics are tabulated by generating pseudo-random data under the null hypothesis of no predictability. ${ }^{14}$

In particular, for the monthly return horizon, we simulate 564 observations of independently and identically distributed Gaussian stock returns, calculate the $R^{2}$ corresponding to the MPP of $q$-period returns using the conditional factors of Section 4.2, record this $R^{2}$, and repeat the same procedure 9,999 times, yielding 10,000 replications. For semi-annual, and annual horizons, we perform similar experiments: we simulate 10,000 independent samples for each horizon, and record the maximum $R^{2}$ for each sample, with sample sizes of 94 , and 47 , respectively.

The simulations yield the finite-sample distribution for the maximal $R^{2}$ under the null hypothesis of no predictability. The features of that distribution are reported for various values of $q$ in Table 9a for unconstrained MPP, and in Table $9 \mathrm{~b}$ for the constrained case. The rows with $q=1$ correspond to a monthly return horizon, those with $q=6$ correspond to semi-annual horizon, and those with $q=12$ correspond to the annual horizon. Finally, the three panels of Tables $9 \mathrm{a}$ and $9 \mathrm{~b}$ correspond to asset vectors with 5,10 , and 11 elements, which match the number of SBU, SIZE, and SECTOR assets, respectively.

Tables $9 \mathrm{a}$ and $9 \mathrm{~b}$ show that when predictability is maximized by combining assets into portfolios, spuriously large $R^{2}$ s may be obtained. With a monthly horizon and 564 observations, the problem is not severe. For example, when $q=1$ and $n=11$, the mean maximal $R^{2}$ is 4.3 percent, a relatively small value. However, as the horizon increases, the problem becomes more serious. With annual returns and eleven assets, the maximal $R^{2}$ distribution for the unconstrained case has a mean of 50.0 percent and a 95 percent critical value of 62.9 percent. Table $9 \mathrm{~b}$ reports similar results for the constrained case-longer-horizon non-overlapping returns can yield large $R^{2}$ even when there is no predictability.

The effects of data-snooping under the null hypothesis can be further quantified by comparing Tables $9 \mathrm{a}$ and $9 \mathrm{~b}$ with Table 10 , in which the percentiles of the finite sample distri-

\footnotetext{
${ }^{14}$ We do have some analytical results for this problem, but they rely heavily on the assumption that returns are multivariate-normal. Moreover, the exact sampling distribution of $R^{2}$ is given by the sum of zonal polynomials which is computationally tractable only for simple special cases. See Lo and MacKinlay (1992) for further details.
} 
bution of the $R^{2}$ for an arbitrary individual asset is reported, also under the null hypothesis of no predictability. For $q=1$ the differences between the distributions in Tables $9 \mathrm{a}$ and $9 \mathrm{~b}$ and the distributions in Table 10 are small--for example, the 95 percent critical value of an individual asset's $R^{2}$ is 2.2 percent, whereas the corresponding critical value for the unconstrained MPP's $R^{2}$ are $3.8,5.5$, and 5.7 percent for five, ten, and eleven assets, respectively. But again the effects of data-snooping become more pronounced as the horizon $q$ increases. Using annual returns with ten assets, the distribution of the unconstrained maximal $R^{2}$ has a 95 percent critical value of 60.6 percent, whereas Table 10 shows that without this maximization, the 95 percent critical value for the $R^{2}$ is only 25.9 percent. These results emphasize the need to interpret portfolio $R^{2}$ s with caution, particularly when the construction of the portfolios is determined by the data [see also Lo and MacKinlay (1990b)].

The statistical significance of the empirical results of Section 4 can now be assessed by relating the maximum sample $R^{2} \mathrm{~s}$ in Tables 5-7 to the empirical null distributions in Tables $9 \mathrm{a}$ and $9 \mathrm{~b}$. The result of such an exercise is clear: the statistical significance of predictability decreases as the observation horizon increases. For the monthly horizon the sample $R^{2} \mathrm{~s}$ are substantially higher than the 95 percent critical values, whereas at the annual horizon they are not.

Of course, this finding need not imply the absence of predictability over longer horizons, but may simply be due to the lack of power in detecting predictability via the maximal $R^{2}$ for long-horizon returns. After all, since we are using non-overlapping returns, our sample size for the annual return horizon is only 47 observations, and given the variability of equity returns, it is not surprising that there is little evidence of predictability in annual data.

\section{Three Out-of-Sample Measures of Predictability.}

Despite the statistical significance of predictability at monthly, semi-annual, and annual horizons, we are still left with the problem of estimating genuine predictability: that portion of the maximal $R^{2}$ not due to deliberate data-snooping. Although it is virtually impossible to provide such a decomposition without placing strong restrictions on the return- and datagenerating processes [see, for example, Foster and Smith (1994) and Lo and MacKinlay 
$(1990 \mathrm{~b})]$, an alternative is to measure the out-of-sample predictability of our MPP. Under the null hypothesis of no predictability our maximization procedure should not impart any statistical biases out-of-sample, but if there is genuine predictability in the MPP it should be apparent in out-of-sample forecasts.

We consider three out-of-sample measures of predictability. First, in a regression framework we examine the relation between the forecast error of a naive constant expected excess return model-an "unconditional" forecast-and a "conditional" forecast minus the naive forecast, where the conditional forecast is conditioned on the factors of Section 4.1. If excess returns are unpredictable, these quantities should be uncorrelated. Second, we employ Merton's (1981) test of market-timing to measure how predictable the MPP is in the context of a simple asset allocation rule. And finally, we present an illustrative profitability calculation for this simple asset allocation rule to gauge the economic significance of the MPP's predictability.

These three measures yield the same conclusion: recent U.S. stock returns contain genuine predictability that is both statistically and economically significant.

\subsection{Naive Versus Conditional Forecasts.}

Denote by $Z_{t}^{*}$ the excess return for the MPP in month $t$ (in excess of the one-month risk-free rate):

$$
Z_{t}^{*} \equiv \hat{\gamma}^{* \prime} R_{t}-R_{f t}
$$

where $R_{t}$ is the vector of primary asset returns, $\hat{\gamma}^{*}$ is the estimated MPP weights, and $R_{f t}$ is the one-month Treasury bill rate. A naive one-step-ahead forecast of $Z_{t}^{*}$ is the weighted average of the (time series) mean excess return for the past returns of each of the primary assets, an unconditional forecast of $Z_{t}^{*}$ which we denote by $\hat{Z}_{t}^{a}$. Now denote by $\hat{Z}_{t}^{b}$ the conditional one-step-ahead forecast of $Z_{t}^{*}$, conditioned on the economic variables of Section 4.1 ,

$$
\hat{Z}_{t}^{b} \equiv \hat{\gamma}^{* \prime}\left(\tilde{Z}_{t}+\hat{\mu}\right)-R_{f t}
$$


where we have added back the estimated mean vector $\hat{\mu}$ of the primary assets since $\tilde{Z}_{t}$ is the conditional forecast of de-meaned returns.

To compare the incremental value of the conditional forecast $\hat{Z}_{t}^{b}$ beyond the naive forecast $\hat{Z}_{t}^{a}$ we estimate the following regression equation:

$$
Z_{t}^{*}-\hat{Z}_{t}^{a}=\beta_{0}+\beta_{1} \cdot\left[\hat{Z}_{t}^{b}-\hat{Z}_{t}^{a}\right]+\epsilon_{t}
$$

If $\hat{Z}_{t}^{b}$ has no forecast power beyond the naive forecast $\hat{Z}_{t}^{a}$, then the estimated coefficient $\hat{\beta}_{1}$ should not be statistically different from zero.

To estimate (36) for each of our three groups of assets, we first estimate the parameters of the conditional factor model (32) and the MPP weights $\hat{\gamma}^{*}$ for monthly SBU, SIZE, and SECTOR asset returns using the first 20 years of our sample, from 1947:1 to 1966:12. The one-month-ahead naive and conditional forecasts, $\hat{Z}_{t}^{a}$ and $\hat{Z}_{t}^{b}$, are then generated month-bymonth beginning in 1967:1 and ending in 1993:12, using a "rolling" procedure where the earliest observation is dropped as each new observation is added, keeping the rolling sample size fixed at 20 years of monthly observations. Therefore, the conditional factor model's parameter estimates and the MPP's weights $\hat{\gamma}^{*}$ are updated monthly.

For the 324-month "out-of-sample" period from 1967:1 to 1993:12, the ordinary least squares estimates of (36) for the three groups of assets are reported in the first sub-panel of Table 11, labelled "monthly:monthly" to emphasize that monthly returns are used to construct the forecast and that monthly returns are being forecasted (see below). For the SBU asset group, the $z$-statistic of the slope coefficient is 1.47 , implying that the power of the one-step-ahead conditional forecast of the MPP return is statistically indistinguishable from that of the naive forecast. However, for both the SIZE and SECTOR groups, the corresponding $z$-statistics are 3.20 and 3.30 , respectively, which suggests that the conditional forecasts do add value in these cases.

To see how the return horizon affects forecast power, we run similar regressions for semiannual and annual return and forecast horizons; we use semi-annual returns to forecast one semi-annual-step ahead, and annual returns to forecast one annual-step ahead. These results are reported in the second and third sub-panels of Table 11, labelled "semi-annual:semi- 
annual" and "annual:annual", respectively. At the semi-annual frequency, conditional forecasts of the MPP add no value to the naive forecasts in any of the asset groups. However, at an annual frequency conditional forecasts seem to add value for SBU and SIZE assets, but not for SECTOR assets.

Finally, in the last two sub-panels of Table 11 we consider the effect of using semiannual and annual returns to forecast monthly returns. For example, semi-annual returns are used to forecast one semi-annual step ahead, but this semi-annual forecast is divided by 6 and is considered the one-month-ahead forecast. This procedure is then repeated in a rolling fashion for each month and the results are reported in Table 11's sub-panel labelled "semi-annual:monthly". A similar procedure is followed in using annual returns to construct monthly forecasts, and these results are reported in Table 11's "annual:monthly" sub-panel. ${ }^{15}$

Interestingly, in both these mixed return/forecast-horizon cases, conditional forecasts add value for all three asset groups, with $z$-statistics ranging from 2.07 (annual returns, SECTOR assets) to 3.85 (annual returns, SBU assets). This suggests the possibility that an optimal forecasting procedure may use returns of one frequency to forecast those of another. In particular, we shall see in Section 6.3 that within the SBU asset group, the economic significance of predictability is considerably greater when annual returns are used to forecast monthly returns than for any other return-horizon/forecast-horizon pair.

These out-of-sample forecast regressions suggest that statistically significant forecastability is present in the MPP, but the degree of predictability varies with the asset groups and with the return and forecast horizon.

\subsection{Merton's Measure of Market Timing.}

As another measure of the out-of-sample predictability of the MPP, consider the following naive asset allocation rule: if next month's MPP return is forecasted to exceed the risk-free rate, then invest the entire portfolio in it; otherwise, invest the entire portfolio in Treasury bills. More formally, let $\theta_{t}$ denote the fraction of the portfolio invested in the MPP in month

\footnotetext{
${ }^{15}$ Other mixed return/forecast-horizon results are available but, in the interest of brevity, are not reported here.
} 
$t$. Then our naive asset allocation strategy is given by:

$$
\theta_{t}=\left\{\begin{array}{lll}
1 & \text { if } \hat{Z}_{t}^{b}>0 \\
0 & \text { if } \hat{Z}_{t}^{b} \leq 0
\end{array}\right.
$$

where $\hat{Z}_{t}^{b}$, defined in (35), is the forecasted excess return on the MPP, in excess of the risk-free rate.

We can measure the out-of-sample predictability of the MPP by using Merton's (1981) framework for measuring market-timing skills. In particular, if the MPP return $Z_{t}^{*}$ were considered the "market", then one could ask whether the asset allocation rule $\theta_{t}$ exhibited positive market-timing performance. Merton (1981) shows that this depends on whether the sum of $p_{1}$ and $p_{2}$ exceeds unity, where:

$$
\begin{aligned}
& p_{1}=\operatorname{Prob}\left(\theta_{t}=0 \mid Z_{t}^{*}>0\right) \\
& p_{2}=\operatorname{Prob}\left(\theta_{t}=1 \mid Z_{t}^{*} \leq 0\right) .
\end{aligned}
$$

These two conditional probabilities are the probabilities that the forecast is correct in "up" and "down" markets, respectively. If $p_{1}+p_{2}$ is greater than 1 , then the forecast $\theta_{t}$ has value, i.e., $Z_{t}^{*}$ is predictable, otherwise it does not.

To perform the Merton test, we use the same 20-year rolling estimation procedure as in Section 6.2 to generate our MPP returns and the one-month-ahead forecasts $\theta_{t}$. From these forecasts and the realized excess returns $Z_{t}^{*}$ of the MPP, we construct the following $2 \times 2$ contingency table:

$$
\begin{gathered}
\theta_{t}>0 \\
\theta_{t} \leq 0
\end{gathered}\left(\begin{array}{cc}
Z_{t}^{*}>0 & Z_{t}^{*} \leq 0 \\
n_{1} & n_{2} \\
N_{1}-n_{1} & N_{2}-n_{2}
\end{array}\right)
$$

where $n_{1}$ is the number of correct forecasts in "up-markets", $n_{2}$ is the number of incorrect forecasts in "down-markets", and $N_{1}$ and $N_{2}$ are the number of up-market and down-market periods, respectively, in the sample. Henriksson and Merton (1981) show that $n_{1}$ has a hypergeometric distribution under the null hypothesis of no market-timing ability, which 
may be approximated by:

$$
n_{1} \stackrel{a}{\sim} \mathrm{N}\left(\frac{n N_{1}}{N}, \frac{n_{1} N_{1} N_{2}(N-n)}{N^{2}(N-1)}\right)
$$

where $N \equiv N_{1}+N_{2}$ and $n \equiv n_{1}+n_{2}$.

Using this sampling theory, we perform nonparametric tests for market-timing ability in our one-step-ahead conditional forecasts in Table 12 for the same return- and forecast-horizon combinations as in Table 11. Table 12 reports the number of forecasts in each category of (39), the estimated sum $\hat{p}_{1}+\hat{p}_{2}$, and the $p$-value based on (40).

The first three sub-panels show that predictability is statistically significant for some asset groups at each horizon: SBU assets at the monthly and annual horizons, and SBU and SECTOR assets at the semi-annual horizon. When semi-annual returns are used to construct monthly forecasts, all three sets of assets have significant predictability, with $p$-values ranging from 0.007 to 0.044 . When annual returns are used to construct monthly forecasts, SBU and SIZE asset groups have significant predictability. Merton's (1981) market-timing measure also confirms the presence of predictability in the MPP.

\subsection{The Profitability of Predictability.}

As a final out-of-sample measure of predictability - one that addresses the economic significance of the MPP's predictability - we compare the total return of a passive or "buy-andhold" investment in the MPP over the entire sample period with the total return of the active asset allocation strategy described in Section 6.2. In particular, for each of the three asset groups, and for the various return- and forecast-horizons, we calculate the following two quantities:

$$
\begin{aligned}
W_{T}^{\text {Passive }} & \equiv \prod_{t=1}^{T}\left(1+R_{t}^{*}\right) \\
W_{T}^{\text {Active }} & \equiv \prod_{t=1}^{T}\left[\theta_{t} \cdot\left(1+R_{t}^{*}\right)+\left(1-\theta_{t}\right) \cdot\left(1+R_{f t}\right)\right]
\end{aligned}
$$

where $\theta_{t}$ is given in (37), $R_{t}^{*}$ is the simple return of the MPP in month $t, W_{T}$ is the end-ofperiod value of an investment of $\$ 1$ over the entire investment period, which we take to be 
the 324-month period from 1967:1 to $1993: 12$ to match the empirical results from Sections 6.1 and 6.2 .

Table 13 shows that the active asset allocation strategy generally outperforms the passive for each of the three asset groups for all return/forecast horizon pairs, yielding a higher mean return, a lower standard deviation of return, and a larger total return $W_{T}$ over the investment period. For example, the monthly passive strategy for the MPP portfolio in the SECTOR group of assets has a mean excess return of 0.82 percent per month and a standard deviation of 6.15 percent per month, whereas the active strategy has a mean excess return of 1.00 percent per month and a standard deviation of 5.26 percent per month. These values imply Sharpe ratios of $\sqrt{12} \times 0.82 / 6.15=0.462$ for the passive SECTOR strategy and $\sqrt{12} \times 1.00 / 5.26=0.659$ for the active SECTOR strategy.

Table 13 also shows that the total returns of the active strategy dominates those of the passive for each of the three asset groups and for all return/forecast horizon pairs. A passive $\$ 1$ monthly investment in the SECTOR asset group at the beginning of 1967:1 yields a total return of $\$ 46.73$ at the end of 1993:12, whereas the corresponding active strategy yields a return of $\$ 99.38$.

Of course, the total returns of the active strategy do not include transactions costs, which can be substantial. To determine the importance of such costs, Table 13 also reports "breakeven" transactions costs, defined to be that percentage cost $100 \times s$ of buying or selling the MPP that would equate the active strategy's total return to the passive strategy's. More formally, if the active strategy requires $k$ switches into or out of the MPP over the 324-month investment period, then the one-way break-even transactions cost $100 \times s$ is defined by:

$$
\begin{aligned}
W_{T}^{\text {Passive }} & =W_{T}^{\text {Active }} \cdot(1-s)^{k} \\
s & =1-\left(\frac{W_{T}^{\text {Passive }}}{W_{T}^{\text {Active }}}\right)^{1 / k} .
\end{aligned}
$$

For a monthly-return/monthly-forecast horizon, Table 13 shows that the number of switches into or out of the MPP portfolio ranges from 58 (SBU) to 80 (SIZE), implying 2 or 3 switches per year on average. This, in turn, implies that the one-way transaction cost would have to 
be somewhere between 0.77 percent (SBU asset group) and 1.19 percent (SIZE asset group) for the active strategy to yield the same total return as the passive.

At the semi-annual-return/semi-annual-forecast horizon, the number of switches declines by construction, dropping to approximately one switch every two-and-a-half years, hence the break-even transactions costs increases dramatically. In this case, the one-way transactions costs would have to be somewhere between 3.88 percent and 4.20 percent to equate the active and passive strategies' total returns.

Now we cannot conclude from Table 13 that the MPP is a "market inefficiency" which is exploitable by the average investor, since we have not formally quantified the (dynamic) risks of the passive and active strategies. Although the active strategy's return has a lower standard deviation and a higher mean, this need not imply that every risk-averse investor would prefer it to the passive strategy. To address this more complex issue, we must specify the investor's preferences and derive his optimal consumption and portfolio rules dynamically, which lies beyond the scope of this paper. Nevertheless, the three out-of-sample measures do indicate the presence of genuine predictability in the MPP, which is both statistically and economically significant. ${ }^{16}$

\section{Conclusion.}

That stock market prices do not follow random walks is now a well-established fact. At issue is the economic sources of predictability in asset returns, since this lies at the heart of several current controversies involving the efficient markets hypothesis, stock market rationality, and the existence of "excessively" profitable trading strategies. Our results show that predictable components are indeed present in the stock market, and that sophisticated forecasting models based on measures of economic conditions do have predictive power. By studying the maximally predictable portfolio, we see that the degree and sources of predictability also vary considerably among assets and over time. Some industries have better predictive power at shorter horizons, whereas others have more power at longer horizons. The changing composition of the maximally predictable portfolio points to important differences

\footnotetext{
${ }^{16}$ See also Breen, Glosten, and Jagannathan (1989, Table IV), who find similar results for monthly equaland value-weighted NYSE stock index returns.
} 
among groups of securities that warrants further investigation. Nevertheless, predictability is both statistically and economically significant in both in sample and out of sample.

We hasten to emphasize that predictabilities need not be a symptom of market inefficiency. While dynamic investment strategies exploiting predictability have yielded higher returns historically, we have not attempted to adjust for risk or for subtle selection biases that might "explain" such phenomena. But despite the ambiguity of the economic sources of predictability, our results suggest that ignoring predictability cannot be rational either. 


\section{Appendix - Proof of Proposition 1}

To maximize $R^{2}(\gamma)$ subject to the constraint that $\gamma^{\prime} \iota=1$, define the following Lagrangian:

$$
\mathcal{L}=R^{2}(\gamma)+\delta\left(1-\gamma^{\prime} \iota\right)
$$

and consider the following first-order conditions:

$$
\begin{aligned}
& \frac{\partial \mathcal{L}}{\partial \gamma}=\frac{2 \tilde{\Gamma}_{0} \gamma^{*}}{\gamma^{* \prime} \Gamma_{0} \gamma^{*}}-\frac{2 \gamma^{* \prime} \tilde{\Gamma}_{0} \gamma^{*}}{\left(\gamma^{* \prime} \Gamma_{0} \gamma^{*}\right)^{2}} \Gamma_{0} \gamma^{*}-\delta^{*} \iota=0 \\
& \frac{\partial \mathcal{L}}{\partial \delta}=1-\gamma^{\prime} \iota=0
\end{aligned}
$$

Pre-multiplying (47) by $\gamma^{*}$ yields:

$$
\gamma^{* \prime \prime} \frac{\partial \mathcal{L}}{\partial \gamma}=0=-\delta^{*}
$$

which indicates that the constraint $\gamma^{\prime} \iota$ is not binding, not surprisingly since we can always rescale $\gamma$ without affecting $R^{2}(\gamma)$. Manipulating $(A 2)$ yields:

$$
\begin{aligned}
\frac{\partial \mathcal{L}}{\partial \gamma} & =\frac{2 \tilde{\Gamma}_{0} \gamma^{*}}{\gamma^{* \prime} \Gamma_{0} \gamma^{*}}-\frac{2 \gamma^{* \prime} \tilde{\Gamma}_{0} \gamma^{*}}{\left(\gamma^{* \prime} \Gamma_{0} \gamma^{*}\right)^{2}} \Gamma_{0} \gamma^{*}=0 \\
\frac{2 \tilde{\Gamma}_{0} \gamma^{*}}{\gamma^{* \prime} \Gamma_{0} \gamma^{*}} & =\frac{2 \gamma^{* \prime} \tilde{\Gamma}_{0} \gamma^{*}}{\left(\gamma^{* \prime} \Gamma_{0} \gamma^{*}\right)^{2}} \Gamma_{0} \gamma^{*} \\
\tilde{\Gamma}_{0} \gamma^{*} & =\frac{\gamma^{* \prime} \tilde{\Gamma}_{0} \gamma^{*}}{\gamma^{* \prime} \Gamma_{0} \gamma^{*}} \Gamma_{0} \gamma^{*}=\lambda^{*} \Gamma_{0} \gamma^{*} .
\end{aligned}
$$

From this, we have:

$$
\Gamma_{0}^{-1} \tilde{\Gamma}_{0} \gamma^{*}=\mathrm{B} \gamma^{*}=\lambda^{*} \gamma^{*}
$$

and since it is straightforward to verify that the second-order condition for a maximum is satisfied by $\gamma^{*}$ when $\gamma^{*}$ is the largest eigenvalue of $B$, we have the result of Gantmacher (1959) and Box and Tiao (1977). 
To constrain the portfolio weights to be nonnegative, we simply add the term $\zeta^{\prime} \gamma$ to the Lagrangian and apply the Kuhn-Tucker Theorem, where $\zeta$ is the vector of Lagrange multipliers for the constraints $\gamma \geq 0$.

Q.E.D. 


\section{References}

Arnott, R., Kelso, C., Kiscadden, S. and R. Macedo, 1989, "Forecasting Factor Returns: An Intriguing Possibility," Journal of Portfolio Management 16, 28-35.

Bessembinder, H. and K. Chan, 1992, "Time-Varying Risk Premia and Forecastable Returns in Futures Markets," Journal of Financial Economics 32, 169-194.

Bossaerts, P. and R. Green, 1989, "A General Equilibrium Model of Changing Risk Premia: Theory and Tests," Review of Financial Studies 2, 467-493.

Box, G. and G. Tiao, 1977, "A Canonical Analysis of Multiple Time Series," Biometrika $64,355-365$.

Breen, W., Glosten, L. and R. Jagannathan, 1989, "Economic Significance of Predictable Variations in Stock Index Returns," Journal of Finance 44, 1177-1189.

Brown, S. and M. Weinstein, 1983, "A New Approach to Testing Arbitrage Pricing Models: The Bilinear Paradigm," Journal of Finance 38, 711-743.

Campbell, J., 1987, "Stock Returns and the Term Structure," Journal of Financial Economics 18, 373-399.

Chamberlain, G., 1983, "Funds, Factors, and Diversification in Arbitrage Pricing Models," Econometrica 51, 1305-1323.

Chamberlain, G. and M. Rothschild, 1983, "Arbitrage, Factor Structure, and Mean Variance Analysis on Large Asset Markets," Econometrica 51, 1281-1304.

Chen, N., 1991, "Financial Investment Opportunities and the Macroeconomy," Journal of Finance 46, 529-554.

Chen, N., Roll, R. and S. Ross, 1986, "Economic Forces and the Stock Market," Journal of Business 59, 383-403.

Chopra, N., Lakonishok, J. and J. Ritter, 1992, "Measuring Abnormal Performance: Do Stocks Overreact?" Journal of Financial Economics 31, 235-268.

Clarke, R., FitzGerald, M., Berent, P. and M. Statman, 1989, "Market Timing with Imperfect Information," Financial Analysts Journal 45, 27-36.

Connor, G. and R. Korajczyk, 1986, "Performance Measurement with the Arbitrage Pricing Theory: A New Framework For Analysis," Journal of Financial Economics 15, 373394.

Connor, G. and R. Korajczyk, 1988, "Risk and Return in an Equilibrium APT: Application of a New Test Methodology," Journal of Financial Economics 21, 255-289. 
Constantinides, G., 1980, "Admissible Uncertainty in the Intertemporal Asset Pricing Model," Journal of Financial Economics 8, 71-86.

DeBondt, W. and R. Thaler, 1985, "Does the Stock Market Overreact?" Journal of Finance $40,793-805$.

Droms, W., 1989 "Market Timing as an Investment Policy," Financial Analysts Journal January/February, 73 .

Engle, R., Lilien, D. and R. Robbins, 1987, "Estimating Time Varying Risk Premia in the Term Structure: the ARCH-M Model," Econometrica 55, 391-407.

Estrella, A. and G. Hardouvelis, 1991, "The Term Structure as a Predictor of Real Economic Activity," Journal of Finance 46, 555-576.

Fama, E. and K. French, 1990, "Business Conditions and Expected Returns on Stocks and Bonds," Journal of Financial Economics 25, 23-49.

Fama, E. and J. MacBeth, 1973, "Risk, Return, and Equilibrium: Empirical Tests," Journal of Political Economy 71, 607-636.

Ferson, W., 1989, "Changes in Expected Security Returns, Risk, and the Level of Interest Rates," Journal of Finance 44, 1191-1217.

Ferson, W., 1990, "Are the Latent Variables in Time-Varying Expected Returns Compensation for Consumption Risk?" Journal of Finance 45, 397-430.

Ferson, W. and C. Harvey, 1991a, "Sources of Predictability in Portfolio Returns," Financial Analysts Journal May-June, 49-56.

Ferson, W. and C. Harvey, 1991b, "The Variation of Economic Risk Premiums," Journal of Political Economy 99, 385-415.

Ferson, W. and C. Harvey, 1993, "The Risk and Predictability of International Equity Returns," Review of Financial Studies 6, 527-566.

Ferson, W., Kandel, S. and R. Stambaugh, 1987, "Tests of Asset Pricing with Time-Varying Expected Risk Premiums and Market Betas," Journal of Finance 42, 201-220.

Ferson, W. and R. Korajczyk, 1993, "Do Arbitrage Pricing Models Explain the Predictability of Stock Returns?" Working Paper No. 115, Department of Finance, Kellogg Graduate School of Management, Northwestern University.

Foster, D. and T. Smith, 1994, "Assessing Goodness-of-Fit of Asset Pricing Models: The Distribution of the Maximal $R^{2}$," Working Paper, Duke University, Durham, NC.

Gantmacher, F., 1959, The Theory of Matrices, Volume I. New York: Chelsea Publishing Company. 
Gibbons, M. and W. Ferson, 1985, "Testing Asset Pricing Models with Changing Expectations and an Unobservable Market Portfolio," Journal of Financial Economics 14, $217-236$.

Goldfeld, S. and R. Quandt, 1973, "A Markov Model for Switching Regressions," Journal of Econometrics 1, 3-16.

Hamilton, J., 1989, "A New Approach to the Economic Analysis of Nonstationary Time Series and the Business Cycle," Econometrica 57, 357-384.

Hardy, D., 1990, "Market Timing and International Diversification," Journal of Portfolio Management 16, 23-27.

Harvey, C., 1989, "Time-Varying Conditional Covariances in Tests of Asset Pricing Models," Journal of Financial Economics 24, 289-317.

Henriksson, R. and R. Merton, 1981, "On Market Timing and Investment Performance II: Statistical Procedures for Evaluating Forecasting Skills," Journal of Business 54, $513-533$.

Iyengar, S. and J. Greenhouse, 1988, "Selection Models and the File Drawer Problem," Statistical Science 3, 109-135.

Jegadeesh, N., 1990, "Evidence of Predictable Behavior of Security Returns," Journal of Finance 45, 881-898.

Kale, J., Hakansson, N. and G. Platt, 1991, "Industry vs. Other Factors in Risk Prediction," Finance Working Paper No. 201, Walter A. Haas School of Business, University of California at Berkeley.

Kandel, S. and R. Stambaugh, 1988, "Modeling Expected Stock Returns for Long and Short Horizons," Rodney L. White Center Working Paper No. 42-88, Wharton School, University of Pennsylvania.

Keim, D. and R. Stambaugh, 1986, "Predicting Returns in the Stock and Bond Markets," Journal of Financial Economics 17, 357-390.

Kester, G., 1990, "Market Timing with Small-Firm Stocks," Financial Analysts Journal $46,63-69$.

King, B., 1966, "Market and Industry Factors in Stock Price Behavior," Journal of Business $39,139-190$.

Leamer, E., 1978, Specification Searches, New York: John Wiley and Sons.

Lee, C. and S. Rahman, 1990, "Market Timing, Selectivity and Mutual Fund Performance: An Empirical Investigation," Journal of Business 63, 261-278.

Lee, C. and S. Rahman, 1991, "New Evidence on Market Timing and Security Selection Skill of Mutual Fund Managers," Journal of Portfolio Management 17, 80-83. 
Lehmann, B., 1990, "Fads, Martingales, and Market Efficiency," Quarterly Journal of Economics 105, 1-28.

Lehmann, B. and D. Modest, 1988, "The Empirical Foundations of the Arbitrage Pricing Theory," Journal of Financial Economics 21, 213-254.

Lo, A. and C. MacKinlay, 1988, "Stock Market Prices Do Not Follow Random Walks: Evidence from a Simple Specification Test," Review of Financial Studies 1, 41-66.

Lo, A. and C. MacKinlay, 1989, "The Size and Power of the Variance Ratio Test in Finite Samples: A Monte Carlo Investigation," Journal of Econometrics 40, 203-238.

Lo, A. and C. MacKinlay, 1990a, "When Are Contrarian Profits Due to Stock Market Overreaction?" Review of Financial Studies 3, 175-206.

Lo, A. and C. MacKinlay, 1990b, "Data-Snooping Biases in Tests of Financial Asset Pricing Models," Review of Financial Studies 3, 431-467.

Lo, A. and C. MacKinlay, 1992, "Maximizing Predictability in the Stock and Bond Markets," Working Paper No. 3450-92-EFA, Sloan School of Management, MIT.

Magnus, J. and H. Neudecker, 1980, "The Elimination Matrix: Some Lemmas and Applications," SIAM Journal on Algebraic and Discrete Methods 1, 422-449.

Merton, R., 1973, "An Intertemporal Capital Asset Pricing Model," Econometrica 41, 867887

Merton, R., 1981, "On Market Timing and Investment Performance I: An Equilibrium Theory of Value for Market Forecasts," Journal of Business 54, 363-406.

Muirhead, R., 1982, Aspects of Multivariate Statistical Theory, New York: John Wiley and Sons.

Reinsel, G., 1983, "Some Results on Multivariate Autoregressive Index Models," Biometrika $70,145-156$.

Richardson, M. and J. Stock, 1990, "Drawing Inferences From Statistics Based on Multiyear Asset Returns," Journal of Financial Economics 25, 323-348.

Roll, R., 1988, "R²," Journal of Finance 43, 541-566.

Roll, R. and S. Ross, 1980, "An Empirical Investigation of the Arbitrage Pricing Theory," Journal of Finance 35, 1073-1103.

Ross, S., 1987, "Regression to the Max," Working Paper, Yale School of Organization and Management.

Rozeff, M., 1984, "Dividend Yields and Equity Risk Premiums," Journal of Portfolio Management , 68-75. 
Samuelson, 1989, "The Judgment of Economic Science on Rational Portfolio Management: Indexing, Timing, and Long-Horizon Effects," Journal of Portfolio Management 16, $4-12$.

Samuelson, 1990, "Asset Allocation Could Be Dangerous to Your Health," Journal of Portfolio Management 16, 5-8.

Sclove, S., 1983, "Time-Series Segmentation: A Model and a Method," Information Sciences 29, 7-25.

Shilling, G., 1992, "Market Timing: Better Than a Buy-and-Hold Strategy," Financial Analysts Journal 48, 46-50.

Sy, W., 1990, "Market Timing: Is It a Folly?" Journal of Portfolio Management 16, 11-16.

Vandell, R. and J. Stevens, 1989, "Evidence of Superior Performance from Timing," Journal of Portfolio Management 15, 38-42.

Velu, R., Reinsel, G. and D. Wichern, 1986, "Reduced Rank Models for Multiple Time Series," Biometrika 73, 105-118.

Wagner, J., Shellans, S. and R. Paul, 1992, "Market Timing Works Where It Matters Most ... In the Real World," Journal of Portfolio Management 18, 86-90.

Weigel, E., 1991, "The Performance of Tactical Asset Allocation," Financial Analysts Journal 47, 63-70.

White, H., 1980, "A Heteroscedasticity-Consistent Covariance Matrix Estimator and a Direct Test for Heteroscedasticity," Econometrica 48, 817-838.

White, H., 1984, Asymptotic Theory for Econometricians. John Wiley and Sons, New York. 


\section{Table 1}

A comparison of the predictability of the portfolio of the first principal component (PC1) and the maximally predictable portfolio (MPP) for a universe of two assets, A and B, with returns satisfying a two-factor linear model where the first factor is white noise and the second factor is an $A R(1)$ with autoregressive coefficient 0.90 . Predictability is measured in two ways: the population $\mathrm{R}^{2}$ of the regression of each asset on the first lag of both factors, and the population squared own-autocorrelation $\rho_{1}^{2}$ of each asset's returns. The return-generating processes for both assets are calibrated to correspond roughly to monthly returns - see the text for details.

\begin{tabular}{ccccc}
\hline Asset & \multicolumn{1}{c}{$\omega_{a}$} & $\omega_{b}$ & $R^{2}$ [Asset] & $\rho_{1}^{2}$ [Asset] \\
\hline \multicolumn{5}{c}{$\delta_{a 2}=0.50$} \\
Stock $A$ & 1.00 & 0.00 & 0.003 & 0.000 \\
Stock $B$ & 0.00 & 1.00 & 0.380 & 0.179 \\
PC1 Portfolio & 0.58 & 0.42 & 0.096 & 0.011 \\
MPP Portfolio & -0.51 & 1.51 & 0.450 & 0.249 \\
& & & & \\
& & & & \\
& 1.00 & 0.00 & 0.355 & 0.155 \\
Stock $A$ & 0.00 & 1.00 & 0.380 & 0.179 \\
Stock $B$ & 0.64 & 0.36 & 0.397 & 0.195 \\
PC1 Portfolio & 0.33 & 0.67 & 0.416 & 0.214 \\
MPP Portfolio & & & & \\
\hline
\end{tabular}


Table 2a

Ordinary least squares regression results for monthly individual asset returns in the SBU asset group from 1947:1 to 1993:12, using the following regressors: DY = dividend yield; DEF = default premium; MAT $=$ maturity premium; SPR $=S \& P 500$ Index total return; SPDY $=S P R \times D Y ; I R T=$ interest rate trend. The five assets in the SBU group are the S\&P 500 Index, a small stock index, a government bond index, a corporate bond index, and a utilities index. Heteroskedasticity-consistent $z$-statistics are given in parentheses.

\begin{tabular}{lccccccccc}
\hline \multicolumn{1}{c}{ Asset } & Constant & DY & DEF & MAT & SPR & SPDY & IRT & D.W. & $R^{2}$ \\
\hline \multirow{2}{*}{ S\&P 500 } & -2.27 & 0.70 & -0.07 & 0.37 & 0.29 & -0.09 & -2.82 & 1.99 & .066 \\
& $(-2.79)$ & $(3.86)$ & $(-0.32)$ & $(2.66)$ & $(1.39)$ & $(-1.72)$ & $(-2.93)$ & & \\
Small & -2.67 & 0.71 & 0.24 & 0.26 & 0.73 & -0.15 & -2.52 & 1.89 & .055 \\
Stocks & $(-2.35)$ & $(2.90)$ & $(.79)$ & $(1.29)$ & $(3.24)$ & $(-2.66)$ & $(-1.80)$ & & \\
Gov't & -1.08 & 0.16 & 0.15 & 0.31 & -0.12 & 0.01 & -0.26 & 1.94 & .044 \\
Bonds & $(-2.35)$ & $(1.75)$ & $(1.04)$ & $(2.71)$ & $(-1.07)$ & $(.31)$ & $(-0.35)$ & & \\
Corp & -1.28 & 0.19 & 0.22 & 0.32 & -0.07 & -0.01 & -0.79 & 1.80 & .068 \\
Bonds & $(-2.85)$ & $(2.14)$ & $(1.54)$ & $(3.02)$ & $(-0.72)$ & $(-0.22)$ & $(-1.23)$ & & \\
Utilities & -2.35 & 0.65 & 0.16 & 0.23 & 0.17 & -0.05 & -1.66 & 1.91 & .055 \\
& $(-3.25)$ & $(4.22)$ & $(.82)$ & $(1.91)$ & $(1.12)$ & $(-1.43)$ & $(-2.15)$ & & \\
\hline
\end{tabular}




\section{Table 2b}

Ordinary least squares regression results for semi-annual individual asset returns in the SBU asset group from 1947:1 to 1993:12, using the following regressors: DY = dividend yield; DEF = default premium; MAT = maturity premium; SPR $=$ S\&P 500 Index total return; SPDY $=$ SPR $\times$ DY; IRT $=$ interest rate trend. The five assets in the SBU group are the S\&P 500 Index, a small stock index, a government bond index, a corporate bond index, and a utilities index. Heteroskedasticity-consistent $z$-statistics are given in parentheses.

\begin{tabular}{lccccccccc}
\hline \multicolumn{1}{c}{ Asset } & Constant & DY & DEF & MAT & SPR & SPDY & IRT & D.W. & $R^{2}$ \\
\hline S\&P 500 & -15.49 & 4.64 & -0.29 & 2.70 & 0.69 & -0.40 & -7.22 & 2.09 & .239 \\
& $(-2.84)$ & $(4.53)$ & $(-0.19)$ & $(3.52)$ & $(.72)$ & $(-1.70)$ & $(-1.21)$ & & \\
Small & -19.81 & 5.46 & 1.90 & 1.97 & 2.80 & -0.91 & -6.95 & 2.14 & .132 \\
Stocks & $(-2.26)$ & $(3.18)$ & $(.75)$ & $(1.46)$ & $(1.72)$ & $(-2.25)$ & $(-0.72)$ & & \\
Gov't & -4.99 & 0.86 & 0.37 & 1.75 & 0.77 & -0.28 & 3.07 & 2.14 & .167 \\
Bonds & $(-1.43)$ & $(1.24)$ & $(.41)$ & $(3.43)$ & $(1.08)$ & $(-1.48)$ & $(.55)$ & & \\
Corp & -6.17 & 1.03 & 0.76 & 1.88 & 1.03 & -0.35 & 5.65 & 2.16 & .233 \\
Bonds & $(-1.82)$ & $(1.51)$ & $(.85)$ & $(3.82)$ & $(1.45)$ & $(-1.84)$ & $(1.05)$ & & \\
Utilities & -14.82 & 4.22 & 0.75 & 1.73 & 0.24 & -0.25 & -5.56 & 1.99 & .231 \\
& $(-3.16)$ & $(4.19)$ & $(.57)$ & $(2.54)$ & $(.22)$ & $(-0.87)$ & $(-1.30)$ & & \\
\hline
\end{tabular}


Table 2c

Ordinary least squares regression results for annual individual asset returns in the SBU asset group from 1947:1 to 1993:12, using the following regressors: DY = dividend yield; DEF = default premium; MAT $=$ maturity premium; SPR $=\mathrm{S} \& \mathrm{P} 500$ Index total return; SPDY $=\mathrm{SPR} \times \mathrm{DY} ; \mathrm{IRT}=$ interest rate trend. The five assets in the SBU group are the S\&P 500 Index, a small stock index, a government bond index, a corporate bond index, and a utilities index. Heteroskedasticity-consistent $z$-statistics are given in parentheses.

\begin{tabular}{|c|c|c|c|c|c|c|c|c|c|}
\hline Asset & Constant & DY & DEF & MAT & SPR & SPDY & IRT & D.W. & $R^{2}$ \\
\hline S\&P 500 & $\begin{array}{l}-35.07 \\
(-3.60)\end{array}$ & $\begin{array}{l}12.88 \\
(4.35)\end{array}$ & $\begin{array}{c}-4.34 \\
(-1.72)\end{array}$ & $\begin{array}{c}2.68 \\
(1.81)\end{array}$ & $\begin{array}{c}6.04 \\
(2.01)\end{array}$ & $\begin{array}{c}-1.81 \\
(-2.30)\end{array}$ & $\begin{array}{l}-28.18 \\
(-2.44)\end{array}$ & 2.12 & .426 \\
\hline $\begin{array}{l}\text { Small } \\
\text { Stocks }\end{array}$ & $\begin{array}{l}-42.12 \\
(-2.45)\end{array}$ & $\begin{array}{l}15.91 \\
(3.92)\end{array}$ & $\begin{array}{c}-3.06 \\
(-0.84)\end{array}$ & $\begin{array}{l}0.83 \\
(.39)\end{array}$ & $\begin{array}{l}10.46 \\
(2.82)\end{array}$ & $\begin{array}{c}-3.10 \\
(-3.22)\end{array}$ & $\begin{array}{l}-58.59 \\
(-2.63)\end{array}$ & 1.87 & .341 \\
\hline $\begin{array}{l}\text { Gov't } \\
\text { Bonds }\end{array}$ & $\begin{array}{l}-11.73 \\
(-1.59)\end{array}$ & $\begin{array}{c}2.35 \\
(1.23)\end{array}$ & $\begin{array}{l}0.46 \\
(.28)\end{array}$ & $\begin{array}{c}3.85 \\
(4.24)\end{array}$ & $\begin{array}{c}2.42 \\
(1.36)\end{array}$ & $\begin{array}{c}-0.74 \\
(-1.48)\end{array}$ & $\begin{array}{l}1.42 \\
(.13)\end{array}$ & 2.21 & .345 \\
\hline $\begin{array}{l}\text { Corp } \\
\text { Bonds }\end{array}$ & $\begin{array}{l}-15.01 \\
(-2.03)\end{array}$ & $\begin{array}{c}2.95 \\
(1.55)\end{array}$ & $\begin{array}{l}1.14 \\
(.81)\end{array}$ & $\begin{array}{c}4.11 \\
(4.89)\end{array}$ & $\begin{array}{c}2.72 \\
(1.52)\end{array}$ & $\begin{array}{c}-0.83 \\
(-1.70)\end{array}$ & $\begin{array}{l}3.53 \\
(.37)\end{array}$ & 2.15 & .425 \\
\hline Utilities & $\begin{array}{l}-38.65 \\
(-4.36)\end{array}$ & $\begin{array}{l}12.58 \\
(5.06)\end{array}$ & $\begin{array}{c}-1.33 \\
(-0.67)\end{array}$ & $\begin{array}{c}2.07 \\
(1.59)\end{array}$ & $\begin{array}{c}6.42 \\
(2.61)\end{array}$ & $\begin{array}{c}-1.88 \\
(-2.86)\end{array}$ & $\begin{array}{l}-16.68 \\
(-1.72)\end{array}$ & 1.84 & .397 \\
\hline
\end{tabular}




\section{Table 3a}

Ordinary least squares regression results for monthly individual asset returns in the SIZE asset group from 1947:1 to $1993: 12$, using the following regressors: DY = dividend yield; DEF = default premium; MAT $=$ maturity premium; SPR $=S \& P 500$ Index total return; SPDY $=S P R \times D Y ;$ IRT $=$ interest rate trend. The ten SIZE assets are portfolios of stocks grouped according to their market value of equity. Heteroskedasticity-consistent $z$-statistics are given in parentheses.

\begin{tabular}{lcclcccccc}
\hline Asset & Constant & DY & DEF & MAT & SPR & SPDY & IRT & D.W. & $R^{2}$ \\
\hline Decile & -2.90 & 0.74 & 0.43 & 0.17 & 1.48 & -0.28 & -2.69 & 1.90 & .082 \\
1 & $(-1.90)$ & $(2.38)$ & $(.95)$ & $(.65)$ & $(4.22)$ & $(-3.40)$ & $(-1.67)$ & & \\
Decile & -2.74 & 0.71 & 0.29 & 0.20 & 1.12 & -0.21 & -2.69 & 1.90 & .073 \\
2 & $(-2.03)$ & $(2.59)$ & $(.73)$ & $(.93)$ & $(4.25)$ & $(-3.32)$ & $(-1.77)$ & & \\
Decile & -3.33 & 0.84 & 0.31 & 0.27 & 0.89 & -0.18 & -2.61 & 1.92 & .064 \\
3 & $(-2.63)$ & $(3.22)$ & $(.90)$ & $(1.30)$ & $(3.64)$ & $(-3.00)$ & $(-1.76)$ & & \\
Decile & -3.01 & 0.80 & 0.24 & 0.24 & 0.80 & -0.16 & -2.54 & 1.92 & .058 \\
4 & $(-2.49)$ & $(3.22)$ & $(.72)$ & $(1.20)$ & $(3.52)$ & $(-2.91)$ & $(-1.81)$ & & \\
Decile & -3.15 & 0.83 & 0.21 & 0.25 & 0.67 & -0.14 & -2.89 & 1.92 & .058 \\
5 & $(-2.72)$ & $(3.46)$ & $(.68)$ & $(1.27)$ & $(3.11)$ & $(-2.63)$ & $(-2.04)$ & & \\
Decile & -3.16 & 0.85 & 0.20 & 0.29 & 0.69 & -0.15 & -3.07 & 1.93 & .066 \\
6 & $(-2.81)$ & $(3.56)$ & $(.67)$ & $(1.53)$ & $(3.34)$ & $(-2.89)$ & $(-2.28)$ & & \\
Decile & -2.83 & 0.78 & 0.17 & 0.30 & 0.58 & -0.13 & -3.24 & 1.91 & .065 \\
7 & $(-2.74)$ & $(3.60)$ & $(.64)$ & $(1.70)$ & $(2.98)$ & $(-2.77)$ & $(-2.54)$ & & \\
Decile & -2.89 & 0.77 & 0.17 & 0.34 & 0.51 & -0.12 & -3.12 & 1.92 & .066 \\
8 & $(-2.96)$ & $(3.71)$ & $(.67)$ & $(2.01)$ & $(2.69)$ & $(-2.65)$ & $(-2.61)$ & & \\
Decile & -2.65 & 0.78 & 0.07 & 0.30 & 0.42 & -0.11 & -3.09 & 1.93 & .062 \\
9 & $(-2.81)$ & $(3.85)$ & $(.28)$ & $(1.86)$ & $(2.19)$ & $(-2.35)$ & $(-2.76)$ & & \\
Decile & -2.15 & 0.66 & -0.09 & 0.37 & 0.28 & -0.08 & -2.68 & 1.99 & .063 \\
10 & $(-2.67)$ & $(3.72)$ & $(-0.44)$ & $(2.67)$ & $(1.34)$ & $(-1.67)$ & $(-2.79)$ & & \\
\hline
\end{tabular}




\section{Table 3b}

Ordinary least squares regression results for semi-annual individual asset returns in the SIZE asset group from 1947:1 to 1993:12, using the following regressors: $D Y=$ dividend yield; DEF = default premium; MAT $=$ maturity premium; SPR $=S \& P 500$ Index total return; SPDY $=S P R \times D Y ; I R T=$ interest rate trend. The ten SIZE assets are portfolios of stocks grouped according to their market value of equity. Heteroskedasticity-consistent $z$-statistics are given in parentheses.

\begin{tabular}{|c|c|c|c|c|c|c|c|c|c|}
\hline Asset & Constant & DY & $\mathrm{DEF}$ & MAT & SPR & SPDY & IRT & D.W. & $R^{2}$ \\
\hline $\begin{array}{l}\text { Decile } \\
1\end{array}$ & $\begin{array}{l}-23.25 \\
(-1.77)\end{array}$ & $\begin{array}{c}6.73 \\
(2.77)\end{array}$ & $\begin{array}{l}2.89 \\
(.73)\end{array}$ & $\begin{array}{l}0.81 \\
(.43)\end{array}$ & $\begin{array}{c}7.87 \\
(3.45)\end{array}$ & $\begin{array}{c}-2.06 \\
(-3.62)\end{array}$ & $\begin{array}{c}-8.99 \\
(-0.69)\end{array}$ & 2.17 & .126 \\
\hline $\begin{array}{l}\text { Decile } \\
2\end{array}$ & $\begin{array}{l}-21.36 \\
(-1.95)\end{array}$ & $\begin{array}{c}5.91 \\
(2.94)\end{array}$ & $\begin{array}{l}2.29 \\
(.71)\end{array}$ & $\begin{array}{l}1.30 \\
(.79)\end{array}$ & $\begin{array}{c}4.90 \\
(2.78)\end{array}$ & $\begin{array}{c}-1.35 \\
(-3.09)\end{array}$ & $\begin{array}{c}-8.45 \\
(-0.73)\end{array}$ & 2.12 & .113 \\
\hline $\begin{array}{l}\text { Decile } \\
3\end{array}$ & $\begin{array}{l}-25.76 \\
(-2.49)\end{array}$ & $\begin{array}{c}6.85 \\
(3.58)\end{array}$ & $\begin{array}{l}2.42 \\
(.79)\end{array}$ & $\begin{array}{c}1.73 \\
(1.20)\end{array}$ & $\begin{array}{c}4.49 \\
(2.66)\end{array}$ & $\begin{array}{c}-1.31 \\
(-3.10)\end{array}$ & $\begin{array}{c}-8.55 \\
(-0.85)\end{array}$ & 2.10 & .155 \\
\hline $\begin{array}{l}\text { Decile } \\
4\end{array}$ & $\begin{array}{l}-22.87 \\
(-2.37)\end{array}$ & $\begin{array}{c}6.28 \\
(3.46)\end{array}$ & $\begin{array}{l}1.89 \\
(.71)\end{array}$ & $\begin{array}{c}1.66 \\
(1.23)\end{array}$ & $\begin{array}{c}3.61 \\
(2.07)\end{array}$ & $\begin{array}{c}-1.07 \\
(-2.53)\end{array}$ & $\begin{array}{c}-7.21 \\
(-0.73)\end{array}$ & 2.13 & .143 \\
\hline $\begin{array}{l}\text { Decile } \\
5\end{array}$ & $\begin{array}{l}-23.77 \\
(-2.50)\end{array}$ & $\begin{array}{c}6.27 \\
(3.59)\end{array}$ & $\begin{array}{l}1.94 \\
(.70)\end{array}$ & $\begin{array}{c}1.82 \\
(1.41)\end{array}$ & $\begin{array}{c}2.64 \\
(1.64)\end{array}$ & $\begin{array}{c}-0.84 \\
(-2.13)\end{array}$ & $\begin{array}{c}-7.62 \\
(-0.79)\end{array}$ & 2.14 & .147 \\
\hline $\begin{array}{l}\text { Decile } \\
6\end{array}$ & $\begin{array}{l}-23.57 \\
(-2.68)\end{array}$ & $\begin{array}{c}6.43 \\
(3.83)\end{array}$ & $\begin{array}{l}1.55 \\
(.62)\end{array}$ & $\begin{array}{c}2.22 \\
(1.84)\end{array}$ & $\begin{array}{c}3.07 \\
(2.00)\end{array}$ & $\begin{array}{c}-0.99 \\
(-2.57)\end{array}$ & $\begin{array}{c}-8.32 \\
(-0.88)\end{array}$ & 2.18 & .178 \\
\hline $\begin{array}{l}\text { Decile } \\
7\end{array}$ & $\begin{array}{l}-20.43 \\
(-2.53)\end{array}$ & $\begin{array}{c}5.66 \\
(3.74)\end{array}$ & $\begin{array}{l}1.37 \\
(.62)\end{array}$ & $\begin{array}{c}2.22 \\
(2.02)\end{array}$ & $\begin{array}{c}2.21 \\
(1.59)\end{array}$ & $\begin{array}{c}-0.76 \\
(-2.24)\end{array}$ & $\begin{array}{c}-7.07 \\
(-0.80)\end{array}$ & 2.20 & .171 \\
\hline $\begin{array}{l}\text { Decile } \\
8\end{array}$ & $\begin{array}{l}-20.12 \\
(-2.71)\end{array}$ & $\begin{array}{c}5.41 \\
(3.90)\end{array}$ & $\begin{array}{l}1.29 \\
(.61)\end{array}$ & $\begin{array}{c}2.39 \\
(2.34)\end{array}$ & $\begin{array}{c}1.77 \\
(1.46)\end{array}$ & $\begin{array}{c}-0.67 \\
(-2.23)\end{array}$ & $\begin{array}{c}-9.25 \\
(-1.16)\end{array}$ & 2.20 & .193 \\
\hline $\begin{array}{l}\text { Decile } \\
9\end{array}$ & $\begin{array}{l}-17.59 \\
(-2.60)\end{array}$ & $\begin{array}{c}5.25 \\
(4.16)\end{array}$ & $\begin{array}{l}0.41 \\
(.21)\end{array}$ & $\begin{array}{c}2.15 \\
(2.34)\end{array}$ & $\begin{array}{c}1.17 \\
(1.11)\end{array}$ & $\begin{array}{c}-0.54 \\
(-2.04)\end{array}$ & $\begin{array}{c}-8.37 \\
(-1.16)\end{array}$ & 2.22 & .203 \\
\hline $\begin{array}{l}\text { Decile } \\
10\end{array}$ & $\begin{array}{l}-14.51 \\
(-2.72)\end{array}$ & $\begin{array}{c}4.33 \\
(4.34)\end{array}$ & $\begin{array}{c}-0.45 \\
(-0.29)\end{array}$ & $\begin{array}{c}2.70 \\
(3.52)\end{array}$ & $\begin{array}{l}0.51 \\
(.54)\end{array}$ & $\begin{array}{c}-0.35 \\
(-1.53)\end{array}$ & $\begin{array}{c}-7.38 \\
(-1.27)\end{array}$ & 2.08 & .235 \\
\hline
\end{tabular}




\section{Table 3c}

Ordinary least squares regression results for annual individual asset returns in the SIZE asset group from 1947:1 to 1993:12, using the following regressors: DY = dividend yield; DEF = default premium; MAT $=$ maturity premium; SPR $=$ S\&P 500 Index total return; SPDY $=$ SPR $\times$ DY; IRT = interest rate trend. The ten SIZE assets are portfolios of stocks grouped according to their market value of equity. Heteroskedasticity-consistent $z$-statistics are given in parentheses.

\begin{tabular}{|c|c|c|c|c|c|c|c|c|c|}
\hline Asset & Constant & DY & DEF & MAT & SPR & SPDY & IRT & D.W. & $R^{2}$ \\
\hline $\begin{array}{l}\text { Decile } \\
1\end{array}$ & $\begin{array}{l}-41.45 \\
(-1.33)\end{array}$ & $\begin{array}{l}18.20 \\
(3.01)\end{array}$ & $\begin{array}{c}-4.67 \\
(-0.97)\end{array}$ & $\begin{array}{l}0.16 \\
(.04)\end{array}$ & $\begin{array}{l}14.35 \\
(2.62)\end{array}$ & $\begin{array}{c}-4.21 \\
(-3.03)\end{array}$ & $\begin{array}{l}-83.15 \\
(-2.43)\end{array}$ & 1.54 & .231 \\
\hline $\begin{array}{l}\text { Decile } \\
2\end{array}$ & $\begin{array}{l}-40.67 \\
(-1.61)\end{array}$ & $\begin{array}{l}16.77 \\
(3.14)\end{array}$ & $\begin{array}{c}-4.37 \\
(-1.04)\end{array}$ & $\begin{array}{l}0.61 \\
(.20)\end{array}$ & $\begin{array}{l}11.81 \\
(2.64)\end{array}$ & $\begin{array}{c}-3.55 \\
(-3.18)\end{array}$ & $\begin{array}{l}-68.83 \\
(-2.35)\end{array}$ & 1.65 & .251 \\
\hline $\begin{array}{l}\text { Decile } \\
3\end{array}$ & $\begin{array}{l}-48.33 \\
(-2.28)\end{array}$ & $\begin{array}{l}17.66 \\
(3.79)\end{array}$ & $\begin{array}{c}-2.50 \\
(-0.67)\end{array}$ & $\begin{array}{l}0.39 \\
(.15)\end{array}$ & $\begin{array}{l}10.19 \\
(2.56)\end{array}$ & $\begin{array}{c}-3.11 \\
(-3.10)\end{array}$ & $\begin{array}{l}-66.77 \\
(-2.47)\end{array}$ & 1.75 & .320 \\
\hline $\begin{array}{l}\text { Decile } \\
4\end{array}$ & $\begin{array}{l}-46.98 \\
(-2.40)\end{array}$ & $\begin{array}{l}17.63 \\
(4.02)\end{array}$ & $\begin{array}{c}-3.53 \\
(-0.96)\end{array}$ & $\begin{array}{l}0.85 \\
(.34)\end{array}$ & $\begin{array}{l}10.33 \\
(2.73)\end{array}$ & $\begin{array}{c}-3.18 \\
(-3.35)\end{array}$ & $\begin{array}{l}-59.48 \\
(-2.66)\end{array}$ & 1.80 & .332 \\
\hline $\begin{array}{l}\text { Decile } \\
5\end{array}$ & $\begin{array}{l}-48.08 \\
(-2.68)\end{array}$ & $\begin{array}{l}17.32 \\
(4.04)\end{array}$ & $\begin{array}{c}-3.68 \\
(-1.05)\end{array}$ & $\begin{array}{l}1.33 \\
(.56)\end{array}$ & $\begin{array}{c}9.84 \\
(2.71)\end{array}$ & $\begin{array}{c}-3.00 \\
(-3.28)\end{array}$ & $\begin{array}{l}-48.49 \\
(-2.24)\end{array}$ & 1.77 & .328 \\
\hline $\begin{array}{l}\text { Decile } \\
6\end{array}$ & $\begin{array}{l}-46.88 \\
(-2.92)\end{array}$ & $\begin{array}{l}16.72 \\
(4.27)\end{array}$ & $\begin{array}{c}-3.05 \\
(-0.96)\end{array}$ & $\begin{array}{l}1.32 \\
(.59)\end{array}$ & $\begin{array}{c}9.45 \\
(2.70)\end{array}$ & $\begin{array}{c}-2.81 \\
(-3.13)\end{array}$ & $\begin{array}{l}-51.08 \\
(-2.64)\end{array}$ & 1.91 & .369 \\
\hline $\begin{array}{l}\text { Decile } \\
7\end{array}$ & $\begin{array}{l}-44.42 \\
(-3.06)\end{array}$ & $\begin{array}{l}16.04 \\
(4.38)\end{array}$ & $\begin{array}{c}-3.21 \\
(-1.06)\end{array}$ & $\begin{array}{l}1.80 \\
(.97)\end{array}$ & $\begin{array}{c}9.26 \\
(3.01)\end{array}$ & $\begin{array}{c}-2.77 \\
(-3.45)\end{array}$ & $\begin{array}{l}-48.10 \\
(-2.79)\end{array}$ & 2.04 & .402 \\
\hline $\begin{array}{l}\text { Decile } \\
8\end{array}$ & $\begin{array}{l}-44.36 \\
(-3.40)\end{array}$ & $\begin{array}{l}15.64 \\
(4.48)\end{array}$ & $\begin{array}{c}-3.28 \\
(-1.14)\end{array}$ & $\begin{array}{c}2.08 \\
(1.18)\end{array}$ & $\begin{array}{c}9.06 \\
(3.08)\end{array}$ & $\begin{array}{c}-2.73 \\
(-3.44)\end{array}$ & $\begin{array}{l}-44.68 \\
(-3.17)\end{array}$ & 1.94 & .442 \\
\hline $\begin{array}{l}\text { Decile } \\
9\end{array}$ & $\begin{array}{l}-36.50 \\
(-3.23)\end{array}$ & $\begin{array}{l}13.75 \\
(4.52)\end{array}$ & $\begin{array}{c}-3.75 \\
(-1.50)\end{array}$ & $\begin{array}{c}1.60 \\
(1.02)\end{array}$ & $\begin{array}{c}6.84 \\
(2.54)\end{array}$ & $\begin{array}{c}-2.07 \\
(-2.90)\end{array}$ & $\begin{array}{l}-41.69 \\
(-3.29)\end{array}$ & 2.09 & .442 \\
\hline $\begin{array}{l}\text { Decile } \\
10\end{array}$ & $\begin{array}{l}-33.18 \\
(-3.48)\end{array}$ & $\begin{array}{l}12.08 \\
(4.20)\end{array}$ & $\begin{array}{c}-4.37 \\
(-1.79)\end{array}$ & $\begin{array}{c}2.69 \\
(1.75)\end{array}$ & $\begin{array}{c}5.96 \\
(1.96)\end{array}$ & $\begin{array}{c}-1.75 \\
(-2.24)\end{array}$ & $\begin{array}{l}-25.56 \\
(-2.22)\end{array}$ & 2.10 & .411 \\
\hline
\end{tabular}




\section{Table 4a}

Ordinary least squares regression results for monthly individual asset returns in the SECTOR asset group from 1947:1 to $1993: 12$, using the following regressors: DY = dividend yield; DEF = default premium; MAT = maturity premium; SPR $=$ S\&P 500 Index total return; SPDY $=$ SPR $\times$ DY; IRT $=$ interest rate trend. The eleven SECTOR assets are portfolios of stocks grouped according to their SIC codes. Heteroskedasticity-consistent $z$-statistics are given in parentheses.

\begin{tabular}{|c|c|c|c|c|c|c|c|c|c|}
\hline Asset & Constant & DY & DEF & MAT & SPR & SPDY & IRT & D.W. & $R^{2}$ \\
\hline Trade & $\begin{array}{c}-3.46 \\
(-3.05)\end{array}$ & $\begin{array}{c}0.74 \\
(3.23)\end{array}$ & $\begin{array}{c}0.52 \\
(1.64)\end{array}$ & $\begin{array}{c}0.35 \\
(1.73)\end{array}$ & $\begin{array}{c}0.80 \\
(3.59)\end{array}$ & $\begin{array}{c}-0.16 \\
(-2.93)\end{array}$ & $\begin{array}{c}-2.84 \\
(-2.08)\end{array}$ & 1.82 & .077 \\
\hline Services & $\begin{array}{c}-3.27 \\
(-2.56)\end{array}$ & $\begin{array}{c}0.80 \\
(3.09)\end{array}$ & $\begin{array}{c}0.39 \\
(1.12)\end{array}$ & $\begin{array}{c}0.30 \\
(1.41)\end{array}$ & $\begin{array}{c}0.88 \\
(3.68)\end{array}$ & $\begin{array}{c}-0.17 \\
(-2.96)\end{array}$ & $\begin{array}{c}-2.52 \\
(-1.80)\end{array}$ & 1.84 & .064 \\
\hline Non-Durables & $\begin{array}{c}-3.17 \\
(-3.16)\end{array}$ & $\begin{array}{c}0.72 \\
(3.41)\end{array}$ & $\begin{array}{c}0.45 \\
(1.58)\end{array}$ & $\begin{array}{c}0.29 \\
(1.69)\end{array}$ & $\begin{array}{c}0.82 \\
(4.12)\end{array}$ & $\begin{array}{c}-0.17 \\
(-3.42)\end{array}$ & $\begin{array}{c}-2.60 \\
(-2.14)\end{array}$ & 1.88 & .080 \\
\hline Construction & $\begin{array}{c}-3.77 \\
(-3.08)\end{array}$ & $\begin{array}{c}0.95 \\
(3.84)\end{array}$ & $\begin{array}{l}0.28 \\
(.82)\end{array}$ & $\begin{array}{c}0.22 \\
(1.02)\end{array}$ & $\begin{array}{c}0.99 \\
(3.75)\end{array}$ & $\begin{array}{c}-0.20 \\
(-3.21)\end{array}$ & $\begin{array}{c}-4.69 \\
(-3.10)\end{array}$ & 1.89 & .092 \\
\hline Capital Goods & $\begin{array}{c}-2.96 \\
(-2.48)\end{array}$ & $\begin{array}{c}0.80 \\
(3.20)\end{array}$ & $\begin{array}{l}0.16 \\
(.50)\end{array}$ & $\begin{array}{c}0.23 \\
(1.14)\end{array}$ & $\begin{array}{c}0.87 \\
(3.77)\end{array}$ & $\begin{array}{c}-0.18 \\
(-3.17)\end{array}$ & $\begin{array}{c}-2.78 \\
(-1.94)\end{array}$ & 1.87 & .061 \\
\hline Durables & $\begin{array}{c}-3.44 \\
(-2.63)\end{array}$ & $\begin{array}{c}0.88 \\
(3.29)\end{array}$ & $\begin{array}{l}0.25 \\
(.73)\end{array}$ & $\begin{array}{c}0.35 \\
(1.64)\end{array}$ & $\begin{array}{c}0.89 \\
(3.56)\end{array}$ & $\begin{array}{c}-0.18 \\
(-3.04)\end{array}$ & $\begin{array}{c}-2.61 \\
(-1.76)\end{array}$ & 1.88 & .060 \\
\hline Fin, RE, Ins & $\begin{array}{c}-4.20 \\
(-3.43)\end{array}$ & $\begin{array}{c}1.03 \\
(4.30)\end{array}$ & $\begin{array}{l}0.27 \\
(.77)\end{array}$ & $\begin{array}{c}0.29 \\
(1.46)\end{array}$ & $\begin{array}{c}0.80 \\
(3.28)\end{array}$ & $\begin{array}{c}-0.16 \\
(-2.79)\end{array}$ & $\begin{array}{c}-3.52 \\
(-2.63)\end{array}$ & 1.89 & .083 \\
\hline Transportation & $\begin{array}{c}-3.21 \\
(-2.57)\end{array}$ & $\begin{array}{c}0.87 \\
(3.10)\end{array}$ & $\begin{array}{l}0.13 \\
(.39)\end{array}$ & $\begin{array}{c}0.29 \\
(1.41)\end{array}$ & $\begin{array}{c}0.81 \\
(3.07)\end{array}$ & $\begin{array}{c}-0.17 \\
(-2.60)\end{array}$ & $\begin{array}{c}-3.47 \\
(-2.27)\end{array}$ & 1.87 & .058 \\
\hline Basic Industries & $\begin{array}{c}-2.21 \\
(-2.05)\end{array}$ & $\begin{array}{c}0.71 \\
(2.99)\end{array}$ & $\begin{array}{l}0.02 \\
(.09)\end{array}$ & $\begin{array}{l}0.16 \\
(.87)\end{array}$ & $\begin{array}{c}0.61 \\
(2.88)\end{array}$ & $\begin{array}{c}-0.13 \\
(-2.46)\end{array}$ & $\begin{array}{c}-3.26 \\
(-2.38)\end{array}$ & 1.96 & .055 \\
\hline Utilities & $\begin{array}{c}-2.35 \\
(-3.25)\end{array}$ & $\begin{array}{c}0.65 \\
(4.22)\end{array}$ & $\begin{array}{l}0.16 \\
(.82)\end{array}$ & $\begin{array}{c}0.23 \\
(1.91)\end{array}$ & $\begin{array}{c}0.17 \\
(1.12)\end{array}$ & $\begin{array}{c}-0.05 \\
(-1.43)\end{array}$ & $\begin{array}{c}-1.66 \\
(-2.15)\end{array}$ & 1.91 & .055 \\
\hline Oil and Coal & $\begin{array}{c}-1.25 \\
(-0.99)\end{array}$ & $\begin{array}{c}0.73 \\
(2.62)\end{array}$ & $\begin{array}{c}-0.30 \\
(-0.92)\end{array}$ & $\begin{array}{c}-0.17 \\
(-0.76)\end{array}$ & $\begin{array}{c}0.67 \\
(2.58)\end{array}$ & $\begin{array}{c}-0.16 \\
(-2.38)\end{array}$ & $\begin{array}{c}-3.12 \\
(-1.64)\end{array}$ & 1.90 & .034 \\
\hline
\end{tabular}


Table 4b

Ordinary least squares regression results for semi-annual individual asset returns in the SECTOR asset group from 1947:1 to 1993:12, using the following regressors: DY = dividend yield; DEF = default premium; MAT $=$ maturity premium; SPR $=$ S\&P 500 Index total return; SPDY $=$ SPR $\times$ DY; IRT $=$ interest rate trend. The eleven SECTOR assets are portfolios of stocks grouped according to their SIC codes. Heteroskedasticityconsistent $z$-statistics are given in parentheses.

\begin{tabular}{|c|c|c|c|c|c|c|c|c|c|}
\hline Asset & Constant & $\mathrm{DY}$ & $\mathrm{DEF}$ & MAT & SPR & SPDY & IRT & D.W. & $R^{2}$ \\
\hline Trade & $\begin{array}{l}-24.83 \\
(-2.46)\end{array}$ & $\begin{array}{c}5.57 \\
(2.97)\end{array}$ & $\begin{array}{c}4.16 \\
(1.43)\end{array}$ & $\begin{array}{c}2.10 \\
(1.43)\end{array}$ & $\begin{array}{c}3.31 \\
(2.03)\end{array}$ & $\begin{array}{c}-0.97 \\
(-2.40)\end{array}$ & $\begin{array}{c}-3.52 \\
(-0.32)\end{array}$ & 2.12 & .142 \\
\hline Services & $\begin{array}{l}-23.68 \\
(-2.11)\end{array}$ & $\begin{array}{c}6.15 \\
(2.89)\end{array}$ & $\begin{array}{c}3.16 \\
(1.00)\end{array}$ & $\begin{array}{c}1.67 \\
(1.08)\end{array}$ & $\begin{array}{c}3.69 \\
(1.89)\end{array}$ & $\begin{array}{c}-1.12 \\
(-2.26)\end{array}$ & $\begin{array}{l}-12.15 \\
(-1.04)\end{array}$ & 2.10 & .132 \\
\hline Non-Durables & $\begin{array}{l}-21.88 \\
(-2.63)\end{array}$ & $\begin{array}{c}5.37 \\
(3.27)\end{array}$ & $\begin{array}{c}2.99 \\
(1.26)\end{array}$ & $\begin{array}{c}1.70 \\
(1.35)\end{array}$ & $\begin{array}{c}3.39 \\
(2.35)\end{array}$ & $\begin{array}{c}-1.02 \\
(-2.78)\end{array}$ & $\begin{array}{l}-10.53 \\
(-1.13)\end{array}$ & 2.10 & .169 \\
\hline Construction & $\begin{array}{l}-27.58 \\
(-2.81)\end{array}$ & $\begin{array}{c}6.95 \\
(3.88)\end{array}$ & $\begin{array}{l}2.49 \\
(.90)\end{array}$ & $\begin{array}{c}1.52 \\
(1.12)\end{array}$ & $\begin{array}{c}4.30 \\
(2.62)\end{array}$ & $\begin{array}{c}-1.15 \\
(-2.81)\end{array}$ & $\begin{array}{c}-1.68 \\
(-0.14)\end{array}$ & 2.24 & .154 \\
\hline Capital Goods & $\begin{array}{l}-22.81 \\
(-2.27)\end{array}$ & $\begin{array}{c}6.18 \\
(3.40)\end{array}$ & $\begin{array}{l}1.77 \\
(.59)\end{array}$ & $\begin{array}{c}1.54 \\
(1.08)\end{array}$ & $\begin{array}{c}3.58 \\
(2.08)\end{array}$ & $\begin{array}{c}-1.04 \\
(-2.50)\end{array}$ & $\begin{array}{c}-8.48 \\
(-0.83)\end{array}$ & 2.23 & .126 \\
\hline Durables & $\begin{array}{l}-26.58 \\
(-2.37)\end{array}$ & $\begin{array}{c}6.87 \\
(3.39)\end{array}$ & $\begin{array}{c}2.63 \\
(.85)\end{array}$ & $\begin{array}{c}1.84 \\
(1.24)\end{array}$ & $\begin{array}{c}4.26 \\
(2.05)\end{array}$ & $\begin{array}{c}-1.19 \\
(-2.42)\end{array}$ & $\begin{array}{c}-6.28 \\
(-0.57)\end{array}$ & 2.12 & .140 \\
\hline Fin, RE, Ins & $\begin{array}{l}-27.58 \\
(-3.05)\end{array}$ & $\begin{array}{c}6.97 \\
(4.05)\end{array}$ & $\begin{array}{l}2.00 \\
(.84)\end{array}$ & $\begin{array}{c}1.79 \\
(1.39)\end{array}$ & $\begin{array}{c}3.21 \\
(2.00)\end{array}$ & $\begin{array}{c}-0.90 \\
(-2.15)\end{array}$ & $\begin{array}{c}-4.24 \\
(-0.42)\end{array}$ & 1.98 & .168 \\
\hline Transportation & $\begin{array}{l}-24.43 \\
(-2.52)\end{array}$ & $\begin{array}{c}6.86 \\
(3.28)\end{array}$ & $\begin{array}{l}1.04 \\
(.39)\end{array}$ & $\begin{array}{c}2.56 \\
(1.84)\end{array}$ & $\begin{array}{c}3.87 \\
(1.60)\end{array}$ & $\begin{array}{c}-1.27 \\
(-2.07)\end{array}$ & $\begin{array}{c}-4.86 \\
(-0.49)\end{array}$ & 1.97 & .158 \\
\hline Basic Industries & $\begin{array}{l}-18.83 \\
(-2.37)\end{array}$ & $\begin{array}{c}5.94 \\
(3.98)\end{array}$ & $\begin{array}{l}0.18 \\
(.08)\end{array}$ & $\begin{array}{c}1.39 \\
(1.20)\end{array}$ & $\begin{array}{c}3.95 \\
(2.80)\end{array}$ & $\begin{array}{c}-1.18 \\
(-3.31)\end{array}$ & $\begin{array}{c}-6.67 \\
(-0.77)\end{array}$ & 2.12 & .163 \\
\hline Utilities & $\begin{array}{l}-14.82 \\
(-3.16)\end{array}$ & $\begin{array}{c}4.22 \\
(4.19)\end{array}$ & $\begin{array}{l}0.75 \\
(.57)\end{array}$ & $\begin{array}{c}1.73 \\
(2.54)\end{array}$ & $\begin{array}{l}0.24 \\
(.22)\end{array}$ & $\begin{array}{c}-0.25 \\
(-0.87)\end{array}$ & $\begin{array}{c}-5.56 \\
(-1.30)\end{array}$ & 1.99 & .231 \\
\hline Oil and Coal & $\begin{array}{l}-10.73 \\
(-1.24)\end{array}$ & $\begin{array}{c}4.93 \\
(2.78)\end{array}$ & $\begin{array}{c}-1.42 \\
(-0.54)\end{array}$ & $\begin{array}{l}0.03 \\
(.02)\end{array}$ & $\begin{array}{l}0.93 \\
(.48)\end{array}$ & $\begin{array}{c}-0.38 \\
(-0.79)\end{array}$ & $\begin{array}{l}-17.13 \\
(-1.53)\end{array}$ & 1.94 & .086 \\
\hline
\end{tabular}


Table 4c

Ordinary least squares regression results for annual individual asset returns in the SECTOR asset group from 1947:1 to 1993:12, using the following regressors: $\mathrm{DY}=$ dividend yield; $\mathrm{DEF}=$ default premium; $\mathrm{MAT}=$ maturity premium; SPR $=\mathrm{S} \& \mathrm{P} 500$ Index total return; SPDY $=\mathrm{SPR} \times \mathrm{DY} ; \mathrm{IRT}=$ interest rate trend. The eleven SECTOR assets are portfolios of stocks grouped according to their SIC codes. Heteroskedasticity-consistent $z$-statistics are given in parentheses.

\begin{tabular}{|c|c|c|c|c|c|c|c|c|c|}
\hline Asset & Constant & DY & DEF & MAT & SPR & SPDY & IRT & D.W. & $R^{2}$ \\
\hline Trade & $\begin{array}{l}-57.42 \\
(-2.58)\end{array}$ & $\begin{array}{l}18.09 \\
(3.68)\end{array}$ & $\begin{array}{l}0.34 \\
(.09)\end{array}$ & $\begin{array}{l}1.95 \\
(.73)\end{array}$ & $\begin{array}{l}12.86 \\
(3.20)\end{array}$ & $\begin{array}{c}-3.76 \\
(-3.70)\end{array}$ & $\begin{array}{l}-51.01 \\
(-2.18)\end{array}$ & 1.62 & .324 \\
\hline Services & $\begin{array}{l}-46.16 \\
(-1.93)\end{array}$ & $\begin{array}{l}18.66 \\
(3.62)\end{array}$ & $\begin{array}{c}-3.87 \\
(-0.99)\end{array}$ & $\begin{array}{l}0.09 \\
(.03)\end{array}$ & $\begin{array}{l}12.92 \\
(3.31)\end{array}$ & $\begin{array}{c}-4.04 \\
(-4.22)\end{array}$ & $\begin{array}{l}-74.54 \\
(-2.85)\end{array}$ & 1.69 & .335 \\
\hline Non-Durables & $\begin{array}{l}-49.54 \\
(-2.86)\end{array}$ & $\begin{array}{l}16.39 \\
(4.13)\end{array}$ & $\begin{array}{c}-0.31 \\
(-0.09)\end{array}$ & $\begin{array}{l}0.77 \\
(.35)\end{array}$ & $\begin{array}{l}10.97 \\
(3.37)\end{array}$ & $\begin{array}{c}-3.25 \\
(-3.89)\end{array}$ & $\begin{array}{l}-57.55 \\
(-3.24)\end{array}$ & 1.92 & .383 \\
\hline Construction & $\begin{array}{l}-50.70 \\
(-2.71)\end{array}$ & $\begin{array}{l}17.23 \\
(3.81)\end{array}$ & $\begin{array}{c}-2.52 \\
(-0.67)\end{array}$ & $\begin{array}{l}1.75 \\
(.69)\end{array}$ & $\begin{array}{c}9.11 \\
(2.52)\end{array}$ & $\begin{array}{c}-2.81 \\
(-3.08)\end{array}$ & $\begin{array}{l}-57.43 \\
(-3.10)\end{array}$ & 1.83 & .345 \\
\hline Captital Goods & $\begin{array}{l}-42.81 \\
(-2.13)\end{array}$ & $\begin{array}{l}16.11 \\
(3.46)\end{array}$ & $\begin{array}{c}-3.73 \\
(-0.93)\end{array}$ & $\begin{array}{l}0.17 \\
(.06)\end{array}$ & $\begin{array}{c}9.20 \\
(2.24)\end{array}$ & $\begin{array}{c}-2.75 \\
(-2.63)\end{array}$ & $\begin{array}{l}-58.77 \\
(-2.51)\end{array}$ & 1.89 & .291 \\
\hline Durables & $\begin{array}{l}-56.88 \\
(-2.59)\end{array}$ & $\begin{array}{l}20.22 \\
(4.32)\end{array}$ & $\begin{array}{c}-3.55 \\
(-0.83)\end{array}$ & $\begin{array}{l}0.67 \\
(.26)\end{array}$ & $\begin{array}{l}13.29 \\
(3.23)\end{array}$ & $\begin{array}{c}-3.89 \\
(-3.70)\end{array}$ & $\begin{array}{l}-63.26 \\
(-2.61)\end{array}$ & 1.83 & .345 \\
\hline Fin, RE, Ins & $\begin{array}{l}-57.06 \\
(-2.85)\end{array}$ & $\begin{array}{l}18.49 \\
(4.28)\end{array}$ & $\begin{array}{c}-2.67 \\
(-0.87)\end{array}$ & $\begin{array}{l}1.21 \\
(.51)\end{array}$ & $\begin{array}{l}11.57 \\
(3.49)\end{array}$ & $\begin{array}{c}-3.21 \\
(-4.02)\end{array}$ & $\begin{array}{l}-44.28 \\
(-2.10)\end{array}$ & 1.47 & .298 \\
\hline Transportation & $\begin{array}{l}-46.13 \\
(-2.56)\end{array}$ & $\begin{array}{l}16.48 \\
(3.49)\end{array}$ & $\begin{array}{c}-3.53 \\
(-0.73)\end{array}$ & $\begin{array}{l}2.19 \\
(.97)\end{array}$ & $\begin{array}{c}7.57 \\
(1.42)\end{array}$ & $\begin{array}{c}-2.39 \\
(-1.64)\end{array}$ & $\begin{array}{l}-63.51 \\
(-3.22)\end{array}$ & 1.90 & .324 \\
\hline Basic Industries & $\begin{array}{l}-37.67 \\
(-2.57)\end{array}$ & $\begin{array}{l}15.16 \\
(3.71)\end{array}$ & $\begin{array}{c}-5.06 \\
(-1.45)\end{array}$ & $\begin{array}{l}1.02 \\
(.52)\end{array}$ & $\begin{array}{c}7.66 \\
(1.97)\end{array}$ & $\begin{array}{c}-2.37 \\
(-2.22)\end{array}$ & $\begin{array}{l}-48.11 \\
(-2.82)\end{array}$ & 2.09 & .342 \\
\hline Utilities & $\begin{array}{l}-38.65 \\
(-4.36)\end{array}$ & $\begin{array}{l}12.58 \\
(5.06)\end{array}$ & $\begin{array}{c}-1.33 \\
(-0.67)\end{array}$ & $\begin{array}{c}2.07 \\
(1.59)\end{array}$ & $\begin{array}{c}6.42 \\
(2.61)\end{array}$ & $\begin{array}{c}-1.88 \\
(-2.86)\end{array}$ & $\begin{array}{l}-16.68 \\
(-1.72)\end{array}$ & 1.84 & .397 \\
\hline Oil and Coal & $\begin{array}{l}-24.66 \\
(-1.05)\end{array}$ & $\begin{array}{l}13.32 \\
(1.99)\end{array}$ & $\begin{array}{c}-7.56 \\
(-1.63)\end{array}$ & $\begin{array}{c}-3.75 \\
(-0.94)\end{array}$ & $\begin{array}{c}7.93 \\
(1.32)\end{array}$ & $\begin{array}{c}-1.91 \\
(-1.24)\end{array}$ & $\begin{array}{l}-26.39 \\
(-0.82)\end{array}$ & 1.90 & .164 \\
\hline
\end{tabular}


Table 5

Conditional expected return of the maximally predictable portfolio for the SBU group from 1947:1 to 1993:12, using the following regressors: $\mathrm{DY}=$ dividend yield; $\mathrm{DEF}=$ default premium; $\mathrm{MAT}=$ maturity premium; $\mathrm{SPR}=\mathrm{S} \& \mathrm{P} 500$ Index total return; SPDY $=\mathrm{SPR} \times \mathrm{DY} ; \mathrm{IRT}=$ interest rate trend. The five SBU assets are: the S\&P500 Index, a small stock index, a government bond index, a corporate bond index, and a utilities index. Heteroskedasticity-consistent $z$-statistics are given in parentheses.

\begin{tabular}{lccccccccc}
\hline \multicolumn{1}{c}{ Asset } & Constant & DY & DEF & MAT & SPR & SPDY & IRT & D.W. & $R^{2}$ \\
\hline Monthly & -1.50 & 0.35 & 0.05 & 0.38 & -0.11 & -0.01 & -1.76 & 1.85 & .106 \\
Unconstrained & $(-2.78)$ & $(3.01)$ & $(.29)$ & $(3.83)$ & $(-0.72)$ & $(-0.36)$ & $(-2.87)$ & & \\
Monthly & -1.61 & 0.36 & 0.12 & 0.34 & 0.05 & -0.03 & -1.48 & 1.89 & .086 \\
Constrained & $(-3.43)$ & $(3.64)$ & $(.86)$ & $(3.59)$ & $(.50)$ & $(-1.19)$ & $(-2.41)$ & & \\
\hline Semi-annual & -7.56 & 1.43 & 0.66 & 2.30 & 1.40 & -0.46 & 6.10 & 2.17 & .309 \\
Unconstrained & $(-2.01)$ & $(1.95)$ & $(.68)$ & $(4.90)$ & $(2.11)$ & $(-2.59)$ & $(1.05)$ & & \\
Semi-annual & -9.52 & 2.33 & 0.38 & 2.18 & 0.91 & -0.37 & 1.03 & 2.07 & .298 \\
Constrained & $(-2.73)$ & $(3.42)$ & $(.41)$ & $(4.78)$ & $(1.42)$ & $(-2.16)$ & $(.21)$ & \\
\hline Annual & -22.05 & 6.53 & -0.58 & 3.34 & 4.36 & -1.31 & -11.27 & 2.06 & .497 \\
Unconstrained & $(-3.91)$ & $(4.28)$ & $(-0.48)$ & $(4.09)$ & $(2.89)$ & $(-3.34)$ & $(-1.70)$ & \\
Annual & -22.05 & 6.53 & -0.58 & 3.34 & 4.36 & -1.31 & -11.27 & 2.06 & .497 \\
Constrained & $(-3.91)$ & $(4.28)$ & $(-0.48)$ & $(4.09)$ & $(2.89)$ & $(-3.34)$ & $(-1.70)$ &
\end{tabular}




\section{Table 6}

Conditional expected return of the maximally predictable portfolio for the SIZE group from 1947:1 to 1993:12, using the following regressors: $\mathrm{DY}=$ dividend yield; $\mathrm{DEF}=$ default premium; $\mathrm{MAT}=$ maturity premium; $\mathrm{SPR}=\mathrm{S} \& \mathrm{P} 500$ Index total return; SPDY $=\mathrm{SPR} \times \mathrm{DY} ; \mathrm{IRT}=$ interest rate trend. The ten SIZE assets are portfolios of stocks grouped according to their market value of equity. Heteroskedasticity-consistent $z$-statistics are given in parentheses.

\begin{tabular}{|c|c|c|c|c|c|c|c|c|c|}
\hline Asset & Constant & DY & DEF & MAT & SPR & SPDY & IRT & D.W. & $R^{2}$ \\
\hline $\begin{array}{l}\text { Unconstrained } \\
\text { Monthly }\end{array}$ & $\begin{array}{c}-0.08 \\
(-0.01)\end{array}$ & $\begin{array}{c}-0.70 \\
(-0.41)\end{array}$ & $\begin{array}{c}2.58 \\
(1.09)\end{array}$ & $\begin{array}{c}-0.03 \\
(-0.02)\end{array}$ & $\begin{array}{c}9.47 \\
(4.06)\end{array}$ & $\begin{array}{c}-1.60 \\
(-3.06)\end{array}$ & $\begin{array}{c}-6.24 \\
(-0.90)\end{array}$ & 1.96 & .116 \\
\hline $\begin{array}{l}\text { Constrained } \\
\text { Monthly }\end{array}$ & $\begin{array}{c}-2.90 \\
(-1.90)\end{array}$ & $\begin{array}{c}0.74 \\
(2.38)\end{array}$ & $\begin{array}{l}0.43 \\
(.95)\end{array}$ & $\begin{array}{l}0.17 \\
(.65)\end{array}$ & $\begin{array}{c}1.48 \\
(4.22)\end{array}$ & $\begin{array}{c}-0.28 \\
(-3.40)\end{array}$ & $\begin{array}{c}-2.69 \\
(-1.67)\end{array}$ & 1.90 & .082 \\
\hline $\begin{array}{l}\text { Unconstrained } \\
\text { Semi-annual }\end{array}$ & $\begin{array}{r}-109.05 \\
(-3.65)\end{array}$ & $\begin{array}{l}21.92 \\
(3.22)\end{array}$ & $\begin{array}{l}19.70 \\
(2.38)\end{array}$ & $\begin{array}{l}16.37 \\
(3.03)\end{array}$ & $\begin{array}{l}41.81 \\
(4.97)\end{array}$ & $\begin{array}{l}-11.41 \\
(-5.43)\end{array}$ & $\begin{array}{l}-63.02 \\
(-1.90)\end{array}$ & 2.06 & .357 \\
\hline $\begin{array}{l}\text { Constrained } \\
\text { Semi-annual }\end{array}$ & $\begin{array}{l}-14.51 \\
(-2.72)\end{array}$ & $\begin{array}{c}4.33 \\
(4.34)\end{array}$ & $\begin{array}{c}-0.45 \\
(-0.29)\end{array}$ & $\begin{array}{c}2.70 \\
(3.52)\end{array}$ & $\begin{array}{l}0.51 \\
(.54)\end{array}$ & $\begin{array}{c}-0.35 \\
(-1.53)\end{array}$ & $\begin{array}{c}-7.38 \\
(-1.27)\end{array}$ & 2.08 & .235 \\
\hline $\begin{array}{l}\text { Unconstrained } \\
\text { Annual }\end{array}$ & $\begin{array}{r}-112.73 \\
(-4.78)\end{array}$ & $\begin{array}{l}30.08 \\
(5.02)\end{array}$ & $\begin{array}{l}10.83 \\
(1.95)\end{array}$ & $\begin{array}{l}1.45 \\
(.49)\end{array}$ & $\begin{array}{l}17.91 \\
(3.03)\end{array}$ & $\begin{array}{c}-5.23 \\
(-3.29)\end{array}$ & $\begin{array}{r}-122.31 \\
(-3.79)\end{array}$ & 1.46 & .615 \\
\hline $\begin{array}{l}\text { Constrained } \\
\text { Annual }\end{array}$ & $\begin{array}{l}-39.68 \\
(-3.41)\end{array}$ & $\begin{array}{l}14.40 \\
(4.54)\end{array}$ & $\begin{array}{c}-3.62 \\
(-1.38)\end{array}$ & $\begin{array}{c}1.96 \\
(1.21)\end{array}$ & $\begin{array}{c}7.75 \\
(2.78)\end{array}$ & $\begin{array}{c}-2.33 \\
(-3.13)\end{array}$ & $\begin{array}{l}-40.94 \\
(-3.21)\end{array}$ & 2.04 & .445 \\
\hline
\end{tabular}




\section{Table 7}

Conditional expected return of the maximally predictable portfolio for the SECTOR group from 1947:1 to 1993:12, using the following regressors: $D Y=$ dividend yield; DEF = default premium; MAT = maturity premium; SPR $=$ S\&P 500 Index total return; SPDY $=S P R \times D Y ; I R T=$ interest rate trend. The eleven SECTOR assets are portfolios of stocks grouped according to their SIC codes. Heteroskedasticity-consistent $z$-statistics are given in parentheses.

\begin{tabular}{lccccccccc}
\hline \multicolumn{1}{c}{ Asset } & Constant & DY & DEF & MAT & SPR & SPDY & IRT & D.W. & $R^{2}$ \\
\hline Unconstrained & -6.73 & 1.15 & 1.27 & 0.41 & 1.92 & -0.37 & -7.18 & 1.72 & .120 \\
Monthly & $(-3.50)$ & $(3.03)$ & $(2.14)$ & $(1.20)$ & $(4.20)$ & $(-3.37)$ & $(-3.37)$ & & \\
Constrained & -3.87 & 0.97 & 0.28 & 0.23 & 0.95 & -0.20 & -4.42 & 1.89 & .093 \\
Monthly & $(-3.21)$ & $(4.01)$ & $(.82)$ & $(1.13)$ & $(3.73)$ & $(-3.19)$ & $(-3.03)$ & & \\
\hline Unconstrained & -11.07 & 4.50 & -1.77 & 1.95 & 1.37 & -0.71 & -11.06 & 2.08 & .315 \\
Semi-annual & $(-2.66)$ & $(5.07)$ & $(-1.65)$ & $(2.33)$ & $(1.32)$ & $(-2.95)$ & $(-2.48)$ & \\
Constrained & -16.47 & 4.67 & 0.80 & 1.87 & 0.86 & -0.43 & -5.44 & 2.02 & .245 \\
Semi-annual & $(-3.39)$ & $(4.85)$ & $(.59)$ & $(2.61)$ & $(.88)$ & $(-1.74)$ & $(-1.14)$ & \\
\hline Unconstrained & -50.00 & 18.82 & -4.59 & 1.74 & 11.47 & -3.51 & -46.54 & 1.87 & .525 \\
Annual & $(-4.02)$ & $(6.06)$ & $(-1.59)$ & $(1.18)$ & $(3.80)$ & $(-4.42)$ & $(-3.99)$ & \\
Constrained & -40.68 & 13.99 & -2.33 & 1.76 & 7.35 & -2.18 & -29.44 & 1.87 & .455 \\
Annual & $(-4.31)$ & $(5.55)$ & $(-1.04)$ & $(1.25)$ & $(3.19)$ & $(-3.62)$ & $(-3.14)$ & \\
\hline
\end{tabular}


Table 8

Portfolio weights of the maximally predictable portfolio for the SBU, SIZE, and SECTOR groups from 1947:1 to 1993:12, using the following regressors: $D Y=$ dividend yield; DEF = defaul premium; MAT = maturity premium; SPR $=$ S\&P 500 Index total return; SPDY $=$ SPR $\times$ DY; IRT $=$ interest rate trend.

\begin{tabular}{|c|c|c|c|c|c|c|}
\hline Asset & $\begin{array}{c}\text { Monthly } \\
\text { Unconstrained }\end{array}$ & $\begin{array}{c}\text { Monthly } \\
\text { Constrained }\end{array}$ & $\begin{array}{l}\text { Semi-annual } \\
\text { Unconstrained }\end{array}$ & $\begin{array}{l}\text { Semi-annual } \\
\text { Constrained }\end{array}$ & $\begin{array}{c}\text { Annual } \\
\text { Unconstrained }\end{array}$ & $\begin{array}{c}\text { Annual } \\
\text { Constrained }\end{array}$ \\
\hline \multicolumn{7}{|c|}{ SBU Group } \\
\hline S\&P500 & 0.69 & 0.34 & 0.35 & 0.36 & 0.19 & 0.19 \\
\hline Small Stocks & -0.38 & 0.00 & 0.04 & 0.00 & 0.13 & 0.13 \\
\hline Gov't Bonds & -0.48 & 0.00 & -0.57 & 0.00 & 0.18 & 0.18 \\
\hline Corp Bonds & 1.19 & 0.66 & 1.54 & 0.64 & 0.49 & 0.49 \\
\hline Utilities & -0.02 & 0.00 & -0.35 & 0.00 & 0.01 & 0.01 \\
\hline \multicolumn{7}{|c|}{ SIZE Group } \\
\hline Decile 1 & 4.97 & 1.00 & 6.28 & 0.00 & 1.10 & 0.00 \\
\hline Decile 2 & 11.18 & 0.00 & -10.39 & 0.00 & -4.68 & 0.00 \\
\hline Decile 3 & -4.11 & 0.00 & 12.85 & 0.00 & 4.57 & 0.00 \\
\hline Decile 4 & -7.13 & 0.00 & -9.75 & 0.00 & -0.67 & 0.00 \\
\hline Decile 5 & -13.97 & 0.00 & -21.87 & 0.00 & -5.25 & 0.00 \\
\hline Decile 6 & 8.97 & 0.00 & 16.92 & 0.00 & 2.55 & 0.00 \\
\hline Decile 7 & 5.54 & 0.00 & 1.65 & 0.00 & 2.09 & 0.00 \\
\hline Decile 8 & 7.50 & 0.00 & 26.52 & 0.00 & 6.79 & 0.46 \\
\hline Decile 9 & -12.01 & 0.00 & -20.02 & 0.00 & -3.18 & 0.41 \\
\hline Decile 10 & 0.06 & 0.00 & -1.19 & 1.00 & -2.32 & 0.13 \\
\hline \multicolumn{7}{|c|}{ SECTOR Group } \\
\hline Trade & 0.36 & 0.00 & -0.53 & 0.00 & -0.70 & 0.00 \\
\hline Services & -0.13 & 0.00 & 0.34 & 0.00 & 0.49 & 0.00 \\
\hline Non-Durables & 2.15 & 0.00 & 0.19 & 0.00 & 0.27 & 0.00 \\
\hline Construction & 1.93 & 0.77 & -0.90 & 0.00 & 0.19 & 0.00 \\
\hline Capital Goods & -0.16 & 0.00 & 0.24 & 0.00 & -1.70 & 0.00 \\
\hline Durables & -1.38 & 0.00 & -0.63 & 0.00 & 1.26 & 0.09 \\
\hline Fin, RE, Ins & 0.32 & 0.23 & 0.43 & 0.00 & -0.01 & 0.01 \\
\hline Transportation & 0.22 & 0.00 & 0.35 & 0.17 & 0.01 & 0.06 \\
\hline Basic Industries & -1.12 & 0.00 & 1.08 & 0.00 & 0.62 & 0.18 \\
\hline Utilities & -0.95 & 0.00 & 0.68 & 0.83 & 0.59 & 0.67 \\
\hline Oil and Coal & -0.24 & 0.00 & -0.25 & 0.00 & -0.03 & 0.00 \\
\hline
\end{tabular}




\section{Table 9a}

Simulated finite sample distribution of maximum $R^{2}$ of the maximally predictable portfolio of $N$ assets under the null hypothesis of no predictability, using six variables as predictors. The simulation consists of 10,000 independent replications of 564 independently and identically distributed Gaussian observations for the monthly horizon $(q=1), 94$ observations for the semi-annual horizon $(q=6)$, and 47 observations for the annual horizon $(q=12)$.

\begin{tabular}{cccccccccccc}
\hline $\mathrm{q}$ & Mean & S.D. & Min & Max & $1 \%$ & $5 \%$ & $10 \%$ & $50 \%$ & $90 \%$ & $95 \%$ & $99 \%$ \\
\hline & & & & & & $N=5$ & & & & \\
1 & .027 & .008 & .007 & .071 & .012 & .016 & .018 & .026 & .038 & .042 & .050 \\
6 & .161 & .044 & .043 & .423 & .076 & .096 & .108 & .156 & .220 & .240 & .284 \\
12 & .317 & .078 & .084 & .669 & .164 & .199 & .221 & .312 & .422 & .452 & .517 \\
\hline & & & & & & $N=10$ & & & & & \\
1 & .043 & .010 & .017 & .095 & .024 & .028 & .031 & .042 & .055 & .060 & .069 \\
6 & .247 & .049 & .105 & .477 & .149 & .172 & .187 & .243 & .311 & .333 & .376 \\
12 & .473 & .077 & .232 & .758 & .308 & .350 & .374 & .470 & .573 & .606 & .664 \\
\hline & & & & & & $N=11$ & & & & & \\
1 & .043 & .011 & .014 & .109 & .022 & .027 & .030 & .042 & .057 & .061 & .072 \\
6 & .262 & .049 & .095 & .477 & .162 & .185 & .200 & .259 & .327 & .349 & .392 \\
12 & .500 & .075 & .241 & .769 & .332 & .378 & .404 & .498 & .598 & .629 & .681 \\
\hline
\end{tabular}

\section{Table $9 b$}

Simulated finite sample distribution of maximum $R^{2}$ of the shortsales-constrained maximally predictable portfolio of $N$ assets under the null hypothesis of no predictability, using six variables as predictors. The simulation consists of 10,000 independent replications of 564 independently and identically distributed Gaussian observations for the monthly horizon $(q=1), 94$ observations for the semi-annual horizon $(q=6)$, and 47 observations for the annual horizon $(q=12)$.

\begin{tabular}{cccccccccccc}
\hline $\mathrm{q}$ & Mean & S.D. & Min & Max & $1 \%$ & $5 \%$ & $10 \%$ & $50 \%$ & $90 \%$ & $95 \%$ & $99 \%$ \\
\hline & & & & & & $N=5$ & & & & & \\
1 & .023 & .007 & .005 & .069 & .010 & .013 & .014 & .022 & .033 & .037 & .044 \\
6 & .136 & .042 & .029 & .381 & .060 & .077 & .087 & .131 & .192 & .211 & .255 \\
12 & .269 & .075 & .068 & .606 & .124 & .157 & .177 & .262 & .369 & .402 & .472 \\
\hline & & & & & & $N=10$ & & & & & \\
1 & .033 & .009 & .013 & .080 & .017 & .021 & .023 & .032 & .044 & .048 & .057 \\
6 & .193 & .046 & .062 & .407 & .105 & .125 & .137 & .188 & .255 & .276 & .319 \\
12 & .373 & .079 & .151 & .697 & .214 & .254 & .276 & .368 & .477 & .514 & .577 \\
\hline & & & & & & $N=11$ & & & & & .52 \\
1 & .231 & .360 & .014 & .939 & .019 & .023 & .026 & .037 & .892 & .902 & .918 \\
6 & .202 & .046 & .081 & .425 & .112 & .134 & .147 & .198 & .264 & .285 & .327 \\
12 & .391 & .079 & .132 & .751 & .230 & .269 & .292 & .386 & .495 & .529 & .591 \\
\hline
\end{tabular}


Table 10

Finite sample distribution of $R^{2}$ of a given portfolio under the null hypothesis of no predictability, using six variables as predictors. The distribution is tabulated for 564 independently and identically distributed Gaussian observations for the monthly horizon $(q=1)$, for 94 observations for the semi-annual horizon $(q=6)$, and for 47 observations for the annual horizon $(q=12)$.

\begin{tabular}{cccccccc}
\hline $\mathrm{q}$ & $\mathbf{1 \%}$ & $\mathbf{5 \%}$ & $\mathbf{1 0 \%}$ & $\mathbf{5 0 \%}$ & $90 \%$ & $95 \%$ & $99 \%$ \\
\hline 1 & .002 & .003 & .004 & .010 & .019 & .022 & .030 \\
6 & .010 & .018 & .024 & .058 & .113 & .132 & .172 \\
12 & .021 & .038 & .051 & .120 & .224 & .259 & .330 \\
\hline
\end{tabular}




\section{Table 11}

Out-of-sample evaluation of conditional one-step-ahead forecasts of the maximally predictable portfolio (MPP) using a regression model with six predictors. The conditional forecasts are evaluated by regressing the deviation of the MPP excess return from its unconditional forecast on the deviation of the conditional MPP excess return forecast from the same unconditional forecast (denoted as $\hat{Z}^{b}-\hat{Z}^{a}$ ). Conditional forecasts for the time period 1967:1 to 1993:12 are constructed for three asset groups and for three time horizons. The asset groups are SBU, SIZE, and SECTOR and the time horizons are monthly, semi-annual, and annual. In the first three sub-panels, the forecasts are evaluated using a return horizon equal to the forecast horizon. In the last two sub-panels, semi-annnual and annual returns are used to forecast monthly returns. D.W. is the Durbin-Watson test statistic for dependence in the regression residual. Heteroskedasticity-consistent $z$-statistics are given in parentheses.

\begin{tabular}{|c|c|c|c|c|}
\hline Asset Group & Constant & $\hat{Z}^{b}-\hat{Z}^{a}$ & D.W. & $R^{2}$ \\
\hline \multicolumn{5}{|c|}{ monthly:monthly } \\
\hline SBU & $\begin{array}{c}-0.01 \\
(-0.05)\end{array}$ & $\begin{array}{c}0.32 \\
(1.47)\end{array}$ & 1.91 & .013 \\
\hline SIZE & $\begin{array}{l}-0.64 \\
(-1.46)\end{array}$ & $\begin{array}{c}0.53 \\
(3.20)\end{array}$ & 1.83 & .034 \\
\hline SECTOR & $\begin{array}{c}-0.35 \\
(-0.95)\end{array}$ & $\begin{array}{c}0.51 \\
(3.30)\end{array}$ & 1.71 & .035 \\
\hline \multicolumn{5}{|c|}{ semi-annual:semi-annual } \\
\hline SBU & $\begin{array}{c}-0.29 \\
(-0.23)\end{array}$ & $\begin{array}{l}0.16 \\
(.82)\end{array}$ & 2.03 & .013 \\
\hline SIZE & $\begin{array}{l}-1.68 \\
(-0.80)\end{array}$ & $\begin{array}{c}0.18 \\
(1.21)\end{array}$ & 2.37 & .024 \\
\hline SECTOR & $\begin{array}{l}1.00 \\
(.48) \\
\end{array}$ & $\begin{array}{c}0.23 \\
(1.38) \\
\end{array}$ & 2.11 & .035 \\
\hline \multicolumn{5}{|c|}{ annual:annual } \\
\hline SBU & $\begin{array}{l}-1.31 \\
(-0.43)\end{array}$ & $\begin{array}{c}0.36 \\
(2.38)\end{array}$ & 2.13 & .182 \\
\hline SIZE & $\begin{array}{l}-1.96 \\
(-0.46)\end{array}$ & $\begin{array}{c}0.25 \\
(2.39)\end{array}$ & 1.81 & .104 \\
\hline SECTOR & $\begin{array}{l}-0.45 \\
(-0.09)\end{array}$ & $\begin{array}{c}0.24 \\
(1.67)\end{array}$ & 1.62 & .075 \\
\hline \multicolumn{5}{|c|}{ semi-annual:monthly } \\
\hline SBU & $\begin{array}{l}-0.22 \\
(-1.12)\end{array}$ & $\begin{array}{c}0.56 \\
(3.22)\end{array}$ & 1.85 & .038 \\
\hline SIZE & $\begin{array}{l}-0.40 \\
(-1.41)\end{array}$ & $\begin{array}{c}0.58 \\
(3.53)\end{array}$ & 1.79 & .045 \\
\hline SECTOR & $\begin{array}{l}-0.17 \\
(-0.60)\end{array}$ & $\begin{array}{c}0.39 \\
(2.27) \\
\end{array}$ & 1.68 & .017 \\
\hline \multicolumn{5}{|c|}{ annual:monthly } \\
\hline SBU & $\begin{array}{l}-0.35 \\
(-1.59)\end{array}$ & $\begin{array}{c}0.72 \\
(3.85)\end{array}$ & 1.81 & .052 \\
\hline SIZE & $\begin{array}{c}-0.51 \\
(-1.82)\end{array}$ & $\begin{array}{c}0.64 \\
(3.65)\end{array}$ & 1.75 & .043 \\
\hline SECTOR & $\begin{array}{l}-0.22 \\
(-0.77)\end{array}$ & $\begin{array}{c}0.40 \\
(2.07)\end{array}$ & 1.64 & .013 \\
\hline
\end{tabular}


Table 12

Out-of-sample evaluation of conditional one-step-ahead forecasts of the maximally predictable portfolio (MPP) using Merton's (1981) measure of market timing. The number of outcomes are calculated for each of four possible excess return-forecast outcomes; a positive MPP excess return and a positive MPP conditional forecast, a positive excess return and a non-positive conditional forecast, a non-positive excess return and a positive conditional forecast, and a non-positive excess return and a non-positive conditional forecast. $Z$ denotes the excess return and $\dot{Z}$ denotes the conditional forecast. $\hat{p}_{1}$ is the sample probability of a positive conditional forecast given a positive excess return and $\hat{p}_{2}$ is the sample probability of a non-positive conditional forecast given a non-positive excess return. The $p$-Value is the probability of obtaining at least the number of correct positive conditional forecasts under the null hypothesis of no forecastability. Conditional forecasts for the time period 1967:1 to 1993:12 are constructed for three asset groups and for three time horizons. The asset groups are SBU, SIZE, and SECTOR and the time horizons are monthly, semi-annual, and annual. In the first three sub-panels, the forecasts are evaluated using a ret urn horizon equal to the forecast horizon. In the last two sub-panels, semi-annnual and annual returns are used to forecast monthly returns.

\begin{tabular}{ccccccc}
\hline Asset & $Z>0$ & $Z>0$ & $Z \leq 0$ & $Z \leq 0$ & $\hat{p}_{1}+\hat{p}_{2}$ & $p$-Value \\
Group & $\hat{Z}>0$ & $\hat{Z} \leq 0$ & $\hat{Z}>0$ & $\hat{Z} \leq 0$ & \\
\hline \multicolumn{7}{c}{ monthly:monthly } \\
SBU & 139 & 92 & 40 & 53 & 1.142 & 0.001 \\
SIZE & 127 & 107 & 47 & 43 & 1.017 & 0.349 \\
SECTOR & 137 & 105 & 43 & 39 & 1.032 & 0.226 \\
\hline \multicolumn{7}{c}{ semi-annual:semi-annual } \\
SBU & 25 & 13 & 6 & 10 & 1.241 & 0.017 \\
SIZE & 21 & 13 & 9 & 11 & 1.158 & 0.078 \\
SECTOR & 25 & 10 & 8 & 11 & 1.281 & 0.008 \\
\hline \multicolumn{7}{c}{ annual:annual } \\
SBU & 15 & 4 & 4 & 4 & 1.289 & 0.048 \\
SIZE & 14 & 5 & 4 & 4 & 1.222 & 0.092 \\
SECTOR & 13 & 5 & 6 & 3 & 1.059 & 0.362 \\
\hline \multicolumn{7}{c}{ semi-annual:monthly } \\
SBU & 154 & 97 & 35 & 38 & 1.096 & 0.012 \\
SIZE & 128 & 88 & 55 & 53 & 1.075 & 0.044 \\
SECTOR & 145 & 94 & 40 & 45 & 1.108 & 0.007 \\
\hline \multicolumn{7}{c}{ annual:monthly } \\
SIZE & 160 & 98 & 29 & 37 & 1.121 & 0.002 \\
SECTOR & 130 & 94 & 49 & 51 & 1.078 & 0.038 \\
& 144 & 100 & 41 & 39 & 1.059 & 0.084 \\
\hline \multicolumn{7}{c}{40}
\end{tabular}




\section{Table 13}

Out of sample evaluation of conditional one-step-ahead forecasts of the maximally predictable portfolio (MPP) using a comparison of passive and active investment strategies in the portfolio. Conditional forecasts for the time period 1967:1 to 1993:12 are constructed for three asset groups and for three time horizons. The asset groups are SBU, SIZE, and SECTOR and the time horizons are monthly, semi-annual, and annual. The forecasts are evaluated using a return horizon equal to the forecast horizon. For semi-annnual and annual forecasts a monthly return horizon is also considered. The active strategies invest $100 \%$ in the MPP if the conditional excess return forecast is positive and invest $100 \%$ in treasury bills otherwise. The ending value represents the terminal value of a $\$ 1$ investment over the entire sample. The number of switches is the number of times the active strategy shifted into or out of the MPP. The break-even cost is the one-way percentage transaction cost that equates the active and passive strategy's ending value.

\begin{tabular}{|c|c|c|c|c|c|c|c|c|}
\hline \multirow{2}{*}{$\begin{array}{l}\text { Asset } \\
\text { Group }\end{array}$} & \multicolumn{3}{|c|}{ Passive Strategy } & \multicolumn{3}{|c|}{ Active Strategy } & \multirow{2}{*}{$\begin{array}{l}\text { Number of } \\
\text { Switches }\end{array}$} & \multirow{2}{*}{$\begin{array}{c}\text { Break-Even } \\
\text { Cost }(\%)\end{array}$} \\
\hline & $\begin{array}{l}\text { Mean Excess } \\
\text { Return (\%) }\end{array}$ & $\begin{array}{l}\text { Standard } \\
\text { Dev. (\%) }\end{array}$ & $\begin{array}{l}\text { Ending } \\
\text { Value (\$) }\end{array}$ & $\begin{array}{l}\text { Mean Excess } \\
\text { Return (\%) }\end{array}$ & $\begin{array}{l}\text { Standard } \\
\text { Dev. }(\%)\end{array}$ & $\begin{array}{l}\text { Ending } \\
\text { Value (\$) }\end{array}$ & & \\
\hline \multicolumn{9}{|c|}{ monthly:monthly } \\
\hline SBU & 0.46 & 3.72 & 21.21 & 0.58 & 3.20 & 33.15 & 58 & 0.77 \\
\hline SIZE & 0.76 & 7.65 & 28.98 & 0.96 & 6.17 & 75.57 & 80 & 1.19 \\
\hline SECTOR & 0.82 & 6.15 & 46.73 & 1.00 & 5.26 & 99.38 & 66 & 1.14 \\
\hline \multicolumn{9}{|c|}{ semi-annual:semi-annual } \\
\hline SBU & 1.66 & 9.48 & 11.95 & 2.53 & 7.79 & 20.01 & 13 & 3.89 \\
\hline SIZE & 2.61 & 15.09 & 13.95 & 3.36 & 11.85 & 25.43 & 14 & 4.20 \\
\hline SECTOR & 5.23 & 15.34 & 52.50 & 5.73 & 11.95 & 84.37 & 12 & 3.88 \\
\hline \multicolumn{9}{|c|}{ annual:annual } \\
\hline SBU & 5.93 & 17.57 & 19.44 & 7.98 & 14.26 & 35.70 & 12 & 4.94 \\
\hline SIZE & 8.77 & 22.63 & 30.89 & 9.72 & 18.09 & 48.00 & 10 & 4.31 \\
\hline SECTOR & 10.33 & 25.55 & 40.55 & 10.99 & 22.07 & 58.21 & 12 & 2.97 \\
\hline \multicolumn{9}{|c|}{ semi-annual:monthly } \\
\hline SBU & 0.43 & 3.38 & 20.27 & 0.56 & 2.98 & 32.06 & 34 & 1.34 \\
\hline SIZE & 0.49 & 5.13 & 19.47 & 0.69 & 4.14 & 42.31 & 32 & 2.40 \\
\hline SECTOR & 0.70 & 4.85 & 40.12 & 0.84 & 4.09 & 70.18 & 20 & 2.76 \\
\hline \multicolumn{9}{|c|}{ annual:monthly } \\
\hline SBU & 0.54 & 3.93 & 27.55 & 0.70 & 3.53 & 47.70 & 30 & 1.81 \\
\hline SIZE & 0.46 & 5.03 & 18.01 & 0.66 & 4.09 & 39.14 & 34 & 2.26 \\
\hline SECTOR & 0.67 & 4.99 & 35.01 & 0.78 & 4.24 & 56.30 & 16 & 2.93 \\
\hline
\end{tabular}

